BRANCO, J.R.O. et al. Viabilidade técnico-financeira de implantação do sistema de recria/engorda em uma propriedade de cria de bovinos no Município de Uberlândia-MG. PUBVET, Londrina, V. 5, N. 16, Ed. 163, Art. 1101, 2011.

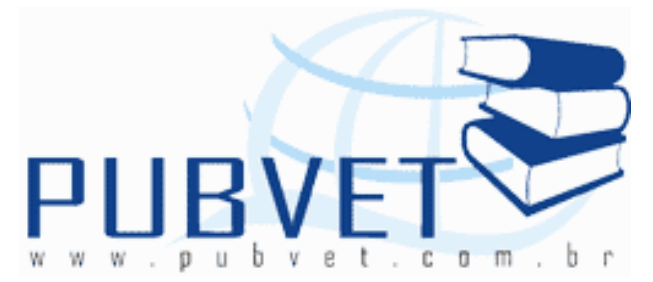

PUBVET, Publicações em Medicina Veterinária e Zootecnia.

\title{
Viabilidade técnico-financeira de implantação do sistema de recria/engorda em uma propriedade de cria de bovinos no Município de Uberlândia-MG
}

José Renato de Oliveira Branco ${ }^{1 *}$, Mariela Silva Moura ${ }^{2}$, Rafael Silveira Carreon $^{1}$, Adriano Pirtouscheg ${ }^{3}$

${ }^{1}$ Médico Veterinário.

${ }^{2}$ Mestranda em Ciências Veterinárias pela Faculdade de Medicina Veterinária, Universidade Federal de Uberlândia. Uberlândia, MG.

${ }^{3}$ Docente da Faculdade de Medicina Veterinária, Universidade Federal de Uberlândia. Uberlândia, MG.

*Autor para correspondência: Rua Ceará, s/n, Bloco 2D, CEP 38400-902, Uberlândia, MG, Brasil. E-mail: joserbranco@hotmail.com

\section{Resumo}

A viabilidade Técnico-Financeira de um projeto busca analisar a capacidade de realização do mesmo. Esse projeto é realizado buscando analisar a capacidade de integração dos processos de produção (Cria, Recria e Engorda) de bovinos em uma propriedade que trabalha com o processo de Cria somente, ressaltando possibilidades técnicas e financeiras. Para isso foi feito uma análise da situação atual da propriedade, levantando capital, receitas, custos e analisando os resultados de forma econômica. Depois foram estimados valores relacionados a custos previstos e receitas, assim como fatores zootécnicos, 
BRANCO, J.R.O. et al. Viabilidade técnico-financeira de implantação do sistema de recria/engorda em uma propriedade de cria de bovinos no Município de Uberlândia-MG. PUBVET, Londrina, V. 5, N. 16, Ed. 163, Art. 1101, 2011.

como alimentação do rebanho, calendário sanitário (vacinação), movimentação de rebanho envolvendo mortalidade, prenhez e natalidade dentro de um período de 10 anos para implantação total dos objetivos. Foi feito um levantamento ano a ano tanto dos fatores zootécnicos como financeiros para implantação de dois processos distintos. O primeiro sem envolver investimentos e o segundo com intensificação no manejo. $O$ primeiro apresentou resultados inviáveis de implantação, tornando desnecessária qualquer comparação com outros sistemas. Já o segundo proporcionou resultados cabíveis a discussão, apresentando vantagens como aumento de capital e aumento da renda líquida e desvantagens como aumento do manejo e longo prazo até recuperação do capital investido.

Palavras-chave: Engorda, Financeiro, Recria, Viabilidade.

\title{
Technical and financial feasibility of implementing systems of growing/fattening property in a brood of cattle in Uberlândia-MG
}

\begin{abstract}
The technical and financial feasibility of a project seeking to examine the capability of achieving the same. This project is carried out trying to analyze the capacity of integration of production processes (Create, growing and fattening) of cattle on a property that works with the process creates only, emphasizing technical and financial possibilities. To this was done an analysis of current situation of the property, raising capital, revenues, costs and analyzing the results of economic order. Estimated values were then related to expected costs and revenues, as well as zootechnical factors such as feeding the flock, schedule health (vaccination), involving movement of livestock, mortality, pregnancy and birth within a period of 10 years for full implementation of the goals. It was a survey done every year of both financial and zootechnical factors for deployment of two separate processes. The first without involving investments and second with intensification in the
\end{abstract}


BRANCO, J.R.O. et al. Viabilidade técnico-financeira de implantação do sistema de recria/engorda em uma propriedade de cria de bovinos no Município de Uberlândia-MG. PUBVET, Londrina, V. 5, N. 16, Ed. 163, Art. 1101, 2011.

management. The first results presented unviable deployment, making unnecessary any comparison with other systems. The second results provided reasonable discussion, showing advantages such as increased capital and increased net income and disadvantages and increase the management and long term to recover the capital invested.

Keywords: Feasibility, Financial, Recreates, fattening

\section{Introdução}

Ao longo dos tempos, a criação bovídea, principalmente no Brasil, ocorre de maneira extensiva para com os resultados a serem obtidos e de certa forma extrativista para com a terra. Devido essa mentalidade oriunda de um período estagnado tecnológica e culturalmente, algumas regiões do Brasil chegaram a se ver obrigada a abandonar suas criações, dada a perda considerável na qualidade da terra, o que acabou por inviabilizar a atividade.

Atualmente, a pecuária nacional passa por um momento delicado, aonde culturas como cana-de-açúcar, soja e outras vem ocupando áreas outrora tomadas por bois. A pecuária bovina busca na conscientização sobre o uso racional da terra e na tecnologia capaz de aumentar a capacidade genética, uma saída para preservação da atividade em regiões tradicionalmente produtoras de carne bovina.

O processo de produção bovina se divide basicamente em três. Cria, Recria e Engorda. É comum hoje em dia, propriedades especificas para cada um dos sistemas citados. O tempo se encarregou de transformar a criação de bovinos em criação de matrizes, bezerras e bezerros, novilhos e novilhas ou bois de engorda. Cada sistema tem suas particularidades e objetivos, porém, todos juntos são responsáveis pelo resultado final. A Cria, com o tratamento dado ao animal até sua desmama tem a mesma ou até mais importância na configuração final de carcaça que um animal recebe após passar pelo processo de engorda, seja esse feito a pasto ou a base de suplementações somente em confinamentos. A Recria é responsável por formar matrizes com boa habilidade 
BRANCO, J.R.O. et al. Viabilidade técnico-financeira de implantação do sistema de recria/engorda em uma propriedade de cria de bovinos no Município de Uberlândia-MG. PUBVET, Londrina, V. 5, N. 16, Ed. 163, Art. 1101, 2011.

materna e animais com boa conformação para entrar na fase final de engorda com capacidade de produzir boa quantidade de carne em menor tempo. A etapa final de Engorda é capaz de provocar um sprint no ganho de peso antes do abate. $O$ fato é que existe uma inter relação muito forte entre os setores de produção que não pode ser facilmente desligada, tornando essa desintegração de setores nas propriedades produtoras vantajosas ou desvantajosas de acordo com o mercado.

Antigamente as fazendas possuíam um rebanho de várias categorias sendo um tratamento para todas. Atualmente existe uma separação com tratos específicos para cada categoria, porém sujeitando o produtor a uma baixa no mercado quanto à reposição de novilhas em certas regiões, preços baixos para venda de bezerros em outras ou baixos aproveitamentos de carcaça por parte de frigoríficos.

O projeto objetiva mostrar se com o avanço tecnológico e cultural existente, é possível criar em uma mesma propriedade, todo o processo de criação bovina de maneira intensiva e financeiramente viável. Busca provar se uma boa utilização da terra, associada a uma genética de qualidade pode integrar os sistemas quantitativamente, aumentando o capital do produtor, e qualitativamente. Isso permitiria ao produtor coordenar o resultado final, animal de qualidade e baixo custo, estando preparado para resolver percalços que em outra situação estariam fora de controle.

Um exemplo seria o produtor que trabalha com Cria que compra novilhas para reposição do lote de matrizes de outro produtor, cuja habilidade materna de seus animais não foi verificada ao longo da criação. O produtor acaba comprando um animal que vai consumir, mas não vai responder conforme o esperado, pois sua genética não é favorável.

Um proprietário de confinamento que compra animais, cujo desmame realizado no processo de Cria, lá atrás, foi precoce por falta de atenção no manejo, estará investindo sem saber, em uma atividade sem retorno, já que 
BRANCO, J.R.O. et al. Viabilidade técnico-financeira de implantação do sistema de recria/engorda em uma propriedade de cria de bovinos no Município de Uberlândia-MG. PUBVET, Londrina, V. 5, N. 16, Ed. 163, Art. 1101, 2011.

esses animais não responderão ao estímulo que será provocado pela suplementação de maneira adequada.

A integração dos processos de produção pode ser uma saída para evitar perdas ao longo do caminho decorridas de terceiros, e o projeto busca viabilizar financeira e tecnicamente essa idéia.

\section{Material e métodos}

O projeto consiste em avaliar a viabilidade de implantação dos métodos de Recria e Engorda na Propriedade Douradinho. Será realizada primeiramente uma análise do desempenho econômico da fazenda dentro das condições atuais e do método de cria utilizado.

Posteriormente será desenvolvido um projeto agropecuário dentro de um período de 10 anos. Avaliando os resultados obtidos dentro de uma exploração extensiva e intensiva de Recria/Engorda poderá ser feita uma comparação. Toma-se como intensivo qualquer investimento que busque otimizar resultados.

A propriedade localiza-se na BR-497 KM-50, Uberlândia- MG. Possui um rebanho composto por animais Nelore de diversas categorias de maneira extensiva. Possui 600 ha. de pastagens, 175 ha. de reservas, 15 ha. de área de preservação permanente e 25 ha. de instalações, totalizando 800 ha.

A formação agrícola da propriedade constituída de quatro forrageiras diferentes, no entanto a área de pastagem é constituída em $99 \%$ de sua totalidade por Brachiaria brizantha $\mathrm{cV}$. Marandú. Outras forrageiras presentes são Brachiaria decumbens, Andropogon guayanus, Brachiaria ruziziensis. Será considerado para efeitos de conta que a área de pastagem é composta $100 \%$ por Brachiaria brizantha $\mathrm{cv}$. Marandú.

Foi feita a análise do desempenho econômico da Fazenda Douradinho utilizando o processo de cria no ano de 2007, da seguinte maneira: 
BRANCO, J.R.O. et al. Viabilidade técnico-financeira de implantação do sistema de recria/engorda em uma propriedade de cria de bovinos no Município de Uberlândia-MG. PUBVET, Londrina, V. 5, N. 16, Ed. 163, Art. 1101, 2011.

Animais

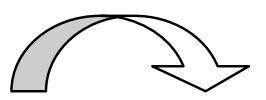

Rebanho Inicial

600 Vacas

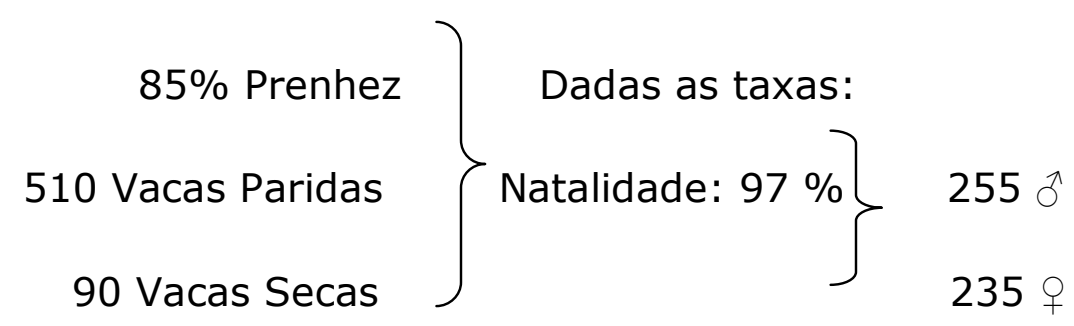

Mortalidade em adultos: $1 \%$

Mortalidade em Novilhas: $1 \%$

Mortalidade em bezerro(a)s: $2 \%$

\section{Rebanho Total}

594 Vacas $\left.\} \begin{array}{c}505 \text { Vacas Paridas } \\ 89 \text { Vacas Secas }\end{array}\right\}-450$ Kg (1 U.A) - 30@ P.V.

99 Novilhas - $337 \mathrm{Kg}(0,75$ U.A) - 22.6@ P.V.

250 Bezerros (até 07 meses) - $157 \mathrm{Kg}(0,35$ U.A) - 10,4@ P.V.

231 Bezerras (até 07 meses) - $145 \mathrm{Kg}(0,32 \mathrm{U} . \mathrm{A})$ - 9,6@ P.V.

15 Touros - $750 \mathrm{Kg}(1,6$ U.A) - 50@ P.V.

Total $-854,7$ U.As.

Total: 1189 animais

10 cavalos de lida - Os cavalos são mantidos nos 25 ha destinados a instalações e se alimentam em pastos separados.

Total: 1199 animais

\section{Alimentação}

Brachiaria brizantha em potencial mínimo, mas não degradada. Produção menor do que 2.5 toneladas dessa pastagem por ha considera-se o pasto em estágio de degradação. O potencial da forrageira encontrado na propriedade é 
BRANCO, J.R.O. et al. Viabilidade técnico-financeira de implantação do sistema de recria/engorda em uma propriedade de cria de bovinos no Município de Uberlândia-MG. PUBVET, Londrina, V. 5, N. 16, Ed. 163, Art. 1101, 2011.

de aproximadamente 9 ton/M.S/há segundo recente mensuração feita pelo proprietário .

Potencial atual do pasto da propriedade: $5.400 .000 \mathrm{Kg} / \mathrm{M} . \mathrm{S} / \mathrm{ano}$.

Capacidade suporte do pasto: 1,36 U.A/ha.

Animais mortos $=9,78$ U.As $/ 2 \times 18=88 \mathrm{~kg} \times 365=32.120 \mathrm{~kg}$

Animais que completam o ciclo $=854,7 \times 18=15.384,6 \times 365=5.615 .379 \mathrm{~kg}$

Total de U.As $=864,5$

Consumo atual da Propriedade: 5.647 .499 Kg/M.S/ano.

Pressão de pastejo: 1,44 U.A/ha.

No momento a quantidade de forragem oferecida pelo pasto não supre a necessidade diária de matéria seca exigida pelos animais. Ocorre uma intensidade de pastejo conhecida como superpastejo.

$5.4000 .00 \mathrm{Kg}-5.647 .499 \mathrm{Kg}=-247.499 \mathrm{Kg}$.

Os $247.499 \mathrm{Kg}$ de matéria seca que faltam para completar a exigência na propriedade são fornecidos via silagem de milho, em especial na seca (85\% na seca e $15 \%$ nas águas), quando o potencial da forrageira decai muito. 0 produtor produz milho ( $35 \%$ matéria seca) em terras próprias vizinhas gastando $R \$ 90,00$ por tonelada de matéria seca e $R \$ 31,50$ por tonelada de "silagem verde" produzida. Há um custo de $\mathrm{R} \$ 22.274,91$ em silagem de milho durante $o$ ano.

\section{Inventário da Propriedade}

Tabela 1 - Uso atual e Valor da Terra

\begin{tabular}{lll}
\hline Uso atual & Área (ha) & Valor (R\$) \\
\hline Pastagens & Próprias & Próprias \\
\hline Reservas & 600 & $3.375 .000,00$ \\
\hline Área Preservação Permanente & 175 & $984.375,00$ \\
\hline Instalações & 15 & $84.375,00$ \\
\hline Total & 25 & $140.625,00$ \\
\hline Remuneração da terra 3\% & 800 & $4.500 .000,00$ \\
\hline
\end{tabular}

Valor do Alqueire: 27.000 
BRANCO, J.R.O. et al. Viabilidade técnico-financeira de implantação do sistema de recria/engorda em uma propriedade de cria de bovinos no Município de Uberlândia-MG.

PUBVET, Londrina, V. 5, N. 16, Ed. 163, Art. 1101, 2011.

\section{Equipamentos}

Trator MASSEY FERGUSON 200280 H.P

Ensiladeira TRAPP 20043 H.P

Triturador Forrageiro TRAPP 2002 3,5 H.P

Grade Aradora (24 discos 26") BALDAN 2004

Grade Niveladora (42 discos 20") BALDAN 2004

Roçadeira TATU MARCHESAN 200270 H.P

Carreta Graneleira RANDON 1999
Horas de Uso /Manutenção (ano)

$1000 \quad 5 \%$

$360 \quad 3 \%$

$360 \quad 5 \%$

$1000 \quad 5 \%$

$1000 \quad 5 \%$

$700 \quad 5 \%$

$500 \quad 5 \%$

\section{Quadro 1- Depreciação de Máquinas e Equipamentos}

\begin{tabular}{|c|c|c|c|c|c|c|c|c|c|c|}
\hline Especificação & $\mathrm{N}^{\mathrm{o}} \cdot \mathrm{HP}$ & Quant. & $\begin{array}{l}\text { Ano de } \\
\text { fabric. }\end{array}$ & Vida Útil & Idade & Valor Atual & $\begin{array}{c}\text { Valor } \\
\text { Inicial }\end{array}$ & $\begin{array}{c}\text { Valor } \\
\text { Residual }\end{array}$ & Manut. & $\begin{array}{c}\text { Deprec. } \\
\text { Anual }\end{array}$ \\
\hline Trator & 80 & 1 & 2002 & 25 & 5 & 32.000 & 40.000 & 4.000 & 2.000 & 1.800 \\
\hline Ensiladeira & 3 & 1 & 2004 & 13 & 3 & $4.230,00$ & 5.500 & 550 & 165 & 495 \\
\hline Triturador & 3,5 & 1 & 2002 & 25 & 5 & $1.148,80$ & 1.436 & 143,6 & 71,8 & 64,62 \\
\hline $\begin{array}{c}\text { Grade } \\
\text { Aradora }\end{array}$ & $\mathrm{x}$ & 1 & 2004 & 23 & 3 & $8.226,08$ & 9.460 & 946 & 473 & 425,7 \\
\hline $\begin{array}{c}\text { Grade } \\
\text { Niveladora }\end{array}$ & $\mathrm{x}$ & 1 & 2004 & 23 & 3 & $5.217,39$ & 6.000 & 600 & 300 & 270 \\
\hline Roçadeira & 70 & 1 & 2002 & 25 & 5 & 5.600 & 7.000 & 700 & 350 & 315 \\
\hline $\begin{array}{c}\text { Carreta } \\
\text { Graneleira } \\
\end{array}$ & $\mathrm{x}$ & 1 & 1999 & 28 & 8 & $13.214,30$ & 18.500 & 1850 & 925 & 832,5 \\
\hline Total & $\mathrm{x}$ & 7 & $\mathrm{x}$ & $\mathrm{x}$ & $\mathrm{x}$ & $69.636,60$ & 87.896 & $8.789,60$ & $4.284,80$ & $3.932,30$ \\
\hline $\begin{array}{l}\text { Remuneração } \\
\text { do capital 6\% }\end{array}$ & $\mathrm{x}$ & $\mathrm{x}$ & $\mathrm{x}$ & $\mathrm{x}$ & $\mathrm{x}$ & 4.178 & 5.273 & 527,3 & 257,08 & 235,9 \\
\hline
\end{tabular}

Instalações (Manutenção anual de 2 a 2,5\%, com uma média de 2,25\% em todas as instalações).

Curral Manejo 2002 (Inclui Brete, embarcadouro, cercas e corredores de aroeira com 10 de espaçamento entre os postes).

Barracão 2002

Casa-sede 1997

Casa-peão 2002

Retiro 1997

Balança 2007 
BRANCO, J.R.O. et al. Viabilidade técnico-financeira de implantação do sistema de recria/engorda em uma propriedade de cria de bovinos no Município de Uberlândia-MG. PUBVET, Londrina, V. 5, N. 16, Ed. 163, Art. 1101, 2011.

\section{Quadro 2 - Depreciação das Instalações}

\begin{tabular}{|c|c|c|c|c|c|c|c|c|c|}
\hline Descrição & Dimens. & Ano constr. & Vida Útil & Idade & Valor Atual & $\begin{array}{c}\text { Valor } \\
\text { Inicial }\end{array}$ & $\begin{array}{c}\text { Valor } \\
\text { Residual }\end{array}$ & Manut & Deprec. \\
\hline $\begin{array}{c}\text { Currais de } \\
\text { Manejo }\end{array}$ & $20 \mathrm{x} 15$ & 2002 & 35 & 5 & $308.571,40$ & 360.000 & 36.000 & 8.000 & 12.000 \\
\hline Barracão & $10 \mathrm{x} 20$ & 2002 & 35 & 5 & $19.285,70$ & 22.500 & 2.500 & 500 & 750 \\
\hline Casa-sede & $15 \mathrm{x} 15$ & 1997 & 40 & 10 & 33.750 & 45.000 & 4.500 & 1.000 & 1.500 \\
\hline Casa-peão & $15 \mathrm{x} 10$ & 2002 & 35 & 5 & $23.142,80$ & 27.000 & 2.700 & 600 & 900 \\
\hline Retiro & $20 \mathrm{x} 15$ & 1997 & 40 & 10 & 50.625 & 67.500 & 6.750 & 1.500 & 2.250 \\
\hline Balança & $4 \mathrm{x} 2,5$ & 2007 & 30 & 0 & 13.140 & 13.140 & 1.340 & 292 & 438 \\
\hline Total & $\mathrm{x}$ & $\mathrm{x}$ & $\mathrm{x}$ & $\mathrm{x}$ & 448.514 & 535.140 & 53.514 & 11.892 & 17.838 \\
\hline $\begin{array}{c}\text { Rem. } \\
\text { capital 6\% }\end{array}$ & $\mathrm{x}$ & $\mathrm{x}$ & $\mathrm{x}$ & $\mathrm{x}$ & $26.910,90$ & $32.108,40$ & $3.210,84$ & 713,52 & $1.070,30$ \\
\hline
\end{tabular}

\section{Insumos consumidos}

Os insumos consumidos são: Sal mineral NUTANE, Sal proteinado NUTANE, Silagem de milho, Energia, Combustível, Telefone, Vacina Febra Aftosa MERIAL, Vacina Brucelose MERIAL, Vacina Raiva MERIAL, Vacina Manqueira (Carbúnculo Sintomático) MERIAL, Vacina Botulismo MERIAL, Vermífugo NOVARTIS.

Vacina Febre Aftosa - Maio (rebanho inteiro) $=1.205$ animais

Novembro (até 24 meses) $=590$ animais.

Total: 1.795 doses.

Vacina Brucelose - (fêmeas 3 a 8 meses) $=235$ animais.

Total: 235 doses.

Vacina Raiva $-($ rebanho inteiro $)=1.205$ animais

Total: 1.205 doses.

Vacina Carbúnculo Sintomático (Manqueira) - (rebanho inteiro) $=1.205$ animais.

Total: 1.205 doses.

Vacina Botulismo $-($ rebanho inteiro $)=1.205$ animais.

Total: 1.205 doses.

Vermífugação - 3 x ao ano (Maio/Julho/Setembro) no rebanho inteiro. 
BRANCO, J.R.O. et al. Viabilidade técnico-financeira de implantação do sistema de recria/engorda em uma propriedade de cria de bovinos no Município de Uberlândia-MG. PUBVET, Londrina, V. 5, N. 16, Ed. 163, Art. 1101, 2011.

São administrados na fazenda dois $\mathrm{ml}$ por U.A em cada vermifugação. Totalizase um total de 1,7 litros em cada etapa. Anualmente administra-se 5 litros no rebanho.

\section{Tabela 2 - Insumos consumidos}

\begin{tabular}{|c|c|c|c|c|c|}
\hline $\begin{array}{l}\text { Tipos de } \\
\text { Insumos }\end{array}$ & Unidade & $\begin{array}{l}\text { Quantidade } \\
\text { (dia) }\end{array}$ & $\begin{array}{l}\text { Quantidade } \\
\text { (180 dias) }\end{array}$ & $\begin{array}{l}\text { Valor } \\
\text { Unitário }\end{array}$ & $\begin{array}{l}\text { Valor } \\
\text { Total }\end{array}$ \\
\hline Sal Mineral & $\begin{array}{l}\text { 70g/U.A/dia } \\
\text { (águas) }\end{array}$ & $\begin{array}{l}60,515 \\
\mathrm{~kg} / \mathrm{dia}\end{array}$ & $\begin{array}{l}10.892,7 \\
\mathrm{~kg} / \\
180 \text { dias }\end{array}$ & $\mathrm{R} \$ 1,08 / \mathrm{kg}$ & $\begin{array}{l}\mathrm{R} \$ \\
11.764,1\end{array}$ \\
\hline Sal Proteinado & $\begin{array}{l}\text { 200g/U.A/dia } \\
\text { (seca) }\end{array}$ & $\begin{array}{l}216,125 \\
\mathrm{~kg} / \mathrm{dia}\end{array}$ & $\begin{array}{l}38.902,50 \\
\mathrm{Kg} / \\
180 \text { dias }\end{array}$ & $\mathrm{R} \$ 1,30 / \mathrm{kg}$ & $\begin{array}{l}\text { R\$ } \\
50.573,25\end{array}$ \\
\hline & & & $\begin{array}{l}\text { Quantidade } \\
\text { (365 dias) }\end{array}$ & & \\
\hline $\begin{array}{l}\text { Silagem milho } \\
\text { (M.S) }\end{array}$ & $\mathrm{kg} / \mathrm{U} . \mathrm{A}$ & $\begin{array}{l}1.937,36 \\
\mathrm{~kg} / \mathrm{dia}\end{array}$ & $\begin{array}{l}707.140 \\
\mathrm{~kg} / \mathrm{ano}\end{array}$ & $\mathrm{R} \$ 90 / \mathrm{t}$ & $\begin{array}{l}\mathrm{R} \$ \\
22.274,91\end{array}$ \\
\hline Energia & kw/mês & & & $\begin{array}{l}\mathrm{R} \$ \\
1.750 / \mathrm{mês}\end{array}$ & $\begin{array}{l}\mathrm{R} \$ \\
21.000\end{array}$ \\
\hline Combustível & Litros/dia & 10 litros/dia & $\begin{array}{l}3.650 \\
\text { Litros/ano }\end{array}$ & $\begin{array}{l}\mathrm{R} \$ \\
2,50 / \text { litro }\end{array}$ & $\begin{array}{l}\mathrm{R} \$ \\
9.125\end{array}$ \\
\hline Telefone & & & & & $\begin{array}{l}\mathrm{R} \$ \\
3.600\end{array}$ \\
\hline $\begin{array}{l}\text { Vacina Febre } \\
\text { Aftosa }\end{array}$ & Dose/animal & - & $\begin{array}{l}1795 \\
\text { Doses/ano }\end{array}$ & $\begin{array}{l}\mathrm{R} \$ \\
1,10 / \text { dose }\end{array}$ & $\begin{array}{l}\mathrm{R} \$ \\
1.974 \\
\end{array}$ \\
\hline Vacina Brucelose & Dose/animal & - & $\begin{array}{l}235 \\
\text { Doses/ano }\end{array}$ & $\begin{array}{l}\mathrm{R} \$ \\
0,50 / \text { dose }\end{array}$ & $\begin{array}{l}\mathrm{R} \$ \\
117,5 \\
\end{array}$ \\
\hline Vacina Raiva & Dose/animal & - & $\begin{array}{l}1.205 \\
\text { Doses/ano }\end{array}$ & $\begin{array}{l}\mathrm{R} \$ \\
0,30 / \text { dose }\end{array}$ & $\begin{array}{l}\mathrm{R} \$ \\
361,5\end{array}$ \\
\hline Vacina Manqueira & Dose/animal & - & $\begin{array}{l}1.205 \\
\text { Doses /ano }\end{array}$ & $\begin{array}{l}\mathrm{R} \$ \\
0,50 / \text { dose }\end{array}$ & $\begin{array}{l}\mathrm{R} \$ \\
602,5\end{array}$ \\
\hline Vacina Botulismo & Dose/animal & - & $\begin{array}{l}1.205 \\
\text { Doses/ano }\end{array}$ & $\begin{array}{l}\mathrm{R} \$ \\
0,40 / \text { dose }\end{array}$ & $\begin{array}{l}\mathrm{R} \$ \\
482,00\end{array}$ \\
\hline Vermífugo & $\begin{array}{l}\text { Litros } \\
\text { (ml/animal) }\end{array}$ & - & 5 Litros/ano & $\begin{array}{l}\text { R\$ } \\
110,00 / \text { litro }\end{array}$ & $\begin{array}{l}\mathrm{R} \$ \\
550,00\end{array}$ \\
\hline $\begin{array}{l}\text { Medicamentos } \\
\text { (vários) }\end{array}$ & $\begin{array}{l}\text { Litros } \\
\text { (ml/animal) }\end{array}$ & - & - & - & $\begin{array}{l}\mathrm{R} \$ \\
6.000,00\end{array}$ \\
\hline Total & & - & - & - & $\begin{array}{l}\mathrm{R} \$ \\
132.025,39\end{array}$ \\
\hline
\end{tabular}


BRANCO, J.R.O. et al. Viabilidade técnico-financeira de implantação do sistema de recria/engorda em uma propriedade de cria de bovinos no Município de Uberlândia-MG. PUBVET, Londrina, V. 5, N. 16, Ed. 163, Art. 1101, 2011.

\section{Tabela 3 - Animais}

\begin{tabular}{llllll}
\hline Éspecie & Categoria & Cabeças & $@$ & $\begin{array}{l}\text { Valor } \\
\text { Unitário } \\
(\mathrm{R} \$)\end{array}$ & $\begin{array}{l}\text { Valor } \\
\text { Total } \\
(\mathrm{R} \$) .\end{array}$ \\
\hline Bovino & Vaca & 594 & 30 & 990 & 588.060 \\
\hline & Novilha & 99 & 22,6 & 740 & 73.260 \\
\hline & $\begin{array}{l}\text { Bezerra } \\
\text { (até 07 } \\
\text { meses) }\end{array}$ & 231 & 9,6 & 410 & 94.710 \\
& Bezerro & 250 & 10,4 & 590 & 147.500 \\
& $\begin{array}{l}\text { (até 07 } \\
\text { meses) }\end{array}$ & & & & \\
\hline & Touro & 15 & 50 & 2.200 & 33.000 \\
\hline Equino & Cavalo & 10 & 32 & 4.360 & 43.600 \\
\hline Total & & 1.191 & - & - & 980.130 \\
\hline $\begin{array}{l}\text { Rem. } \\
\text { Capital } \\
6 \%\end{array}$ & - & - & - & - & $58.807,80$ \\
\hline
\end{tabular}

\section{Tabela 4 - Serviços Contratados}

\begin{tabular}{llllll}
\hline Tipo & Homens/dia & $\begin{array}{l}\text { Dias } \\
\text { trabalhados }\end{array}$ & $\begin{array}{l}\text { Valor } \\
\text { pago/dia } \\
(\mathrm{R} \$)\end{array}$ & INSS & $\begin{array}{l}\text { Total } \\
(\mathrm{R} \$)\end{array}$ \\
\hline Tratorista & 01 & 20 & 40 & 21,6 & 821,6 \\
\hline Peão & 04 & 20 & 35 & 18,9 & $2.875,60$ \\
\hline Total & 05 & 20 & 75 & 40,5 & $3.697,20$ \\
\hline
\end{tabular}


BRANCO, J.R.O. et al. Viabilidade técnico-financeira de implantação do sistema de recria/engorda em uma propriedade de cria de bovinos no Município de Uberlândia-MG. PUBVET, Londrina, V. 5, N. 16, Ed. 163, Art. 1101, 2011.

Tabela 5 - Pagamentos a trabalhadores permanentes e temporários

\begin{tabular}{llllll}
\hline Cargo/Tarefa & Trabalhadores & $\begin{array}{l}\text { Dias } \\
\text { Trabalhados }\end{array}$ & $\begin{array}{l}\text { Salário } \\
\text { Mensal }\end{array}$ & Encargos & $\begin{array}{l}\text { Total } \\
\text { /anual }\end{array}$ \\
\hline Permanentes & & & & & \\
\hline Funcionários & 01 & 275 & 810 & 86,6 & 10.759 \\
\hline Pró-Labore & 01 & 275 & 2000 & 214 & 26.568 \\
\hline Veterinário & 01 & 30 & 810 & 86,6 & 10.759 \\
\hline Sub-Total & 04 & - & - & - & $48.086,2$ \\
\hline Temporários & & & & & \\
\hline Tratorista & 01 & 20 & - & - & 822 \\
\hline Peão & 04 & 20 & - & - & $2.875,60$ \\
\hline Sub-Total & 05 & - & - & - & $3.697,20$ \\
\hline Total & 09 & - & - & - & $51.783,4$ \\
\hline
\end{tabular}

Tabela 6 - Registro de Produção

\begin{tabular}{lllll}
\hline Produto & Unidade & $\begin{array}{l}\text { Produção } \\
\text { Vendida }\end{array}$ & $\begin{array}{l}\text { Preço } \\
\text { Unitário }\end{array}$ & $\begin{array}{l}\text { Valor } \\
\text { Total }\end{array}$ \\
\hline $\begin{array}{l}\text { Matrizes } \\
\text { para } \\
\text { descarte }\end{array}$ & Cab & 89 & 990 & 88.110 \\
\hline Novilhas & Cab & 04 & 740 & 2.960 \\
\hline $\begin{array}{l}\text { Bezerros } \\
\text { (até 07 } \\
\text { meses) }\end{array}$ & Cab & 250 & 590 & 147.500 \\
\hline $\begin{array}{l}\text { Bezerras } \\
\text { (até 07 } \\
\text { meses) }\end{array}$ & Cab & 131 & 410 & 53.710 \\
\hline $\begin{array}{l}\text { Total } \\
\text { Cab }\end{array}$ & 474 & 616,37 & 292.280 \\
\hline
\end{tabular}


BRANCO, J.R.O. et al. Viabilidade técnico-financeira de implantação do sistema de recria/engorda em uma propriedade de cria de bovinos no Município de Uberlândia-MG. PUBVET, Londrina, V. 5, N. 16, Ed. 163, Art. 1101, 2011.

Tabela 7 - Renda Bruta

\begin{tabular}{llll}
\hline Especificação & $\begin{array}{l}\text { Valor } \\
\text { Unitário }\end{array}$ & $\begin{array}{l}\text { Valor } \\
\text { Total }\end{array}$ & $\begin{array}{l}\% \\
\text { Receita }\end{array}$ \\
\hline Renda Bruta & & & \\
\hline $\begin{array}{l}\text { Venda de } \\
\text { cabeças }\end{array}$ & 616,62 & 292.280 & 100 \\
\hline Total & 616,62 & 292.280 & 100 \\
\hline
\end{tabular}

Tabela 8 - Custo de Produção Variável

\begin{tabular}{lllll}
\hline Especificação & Valor Total & $\begin{array}{l}\text { \%Custo } \\
\text { Variável }\end{array}$ & $\begin{array}{l}\text { \%Custo } \\
\text { Total }\end{array}$ & $\begin{array}{l}\text { Valor } \\
\text { Unitário }\end{array}$ \\
\hline $\begin{array}{l}\text { CUSTO DE PRODUÇÃo } \\
\text { VARIÁVEL }\end{array}$ & & & & \\
\hline $\begin{array}{l}\text { Custo Operacional } \\
\text { Variável }\end{array}$ & & & & \\
\hline Mão-de-obra temporária & $3.697,20$ & 0,024 & 0,01 & 7,8 \\
\hline $\begin{array}{l}\text { Manutenção de } \\
\text { máquinas e } \\
\text { equipamentos }\end{array}$ & $4.284,00$ & 0,027 & 0,01 & 9,04 \\
\hline $\begin{array}{l}\text { Manutenção de } \\
\text { instalações }\end{array}$ & 11.892 & 0,07 & 0,03 & 25,09 \\
\hline Sal mineral & $11.764,00$ & 0,07 & 0,03 & 24,81 \\
\hline Sal proteinado & $50.573,25$ & 0,32 & 0,14 & 106,7 \\
\hline Silagem milho & $22.274,00$ & 0,14 & 0,06 & 47 \\
\hline Energia & 21.000 & 0,13 & 0,05 & 44,3 \\
\hline Combustível & 9.125 & 0,06 & 0,02 & 19,25 \\
\hline Telefone & 3.600 & 0,02 & 0,009 & 7,6 \\
\hline Vacinação & $4.087,00$ & 0,02 & 0,01 & 8,62 \\
\hline Vermifugação & 550 & 0,003 & 0,001 & 1,16 \\
\hline Medicamentos & 6.000 & 0,04 & 0,01 & 12,65 \\
\hline Sub-Total & $148.847,45$ & 0,97 & 0,41 & 314,02 \\
\hline $\begin{array}{l}\text { Custo Alternativo } \\
\text { Variável }\end{array}$ & & & & \\
\hline $\begin{array}{l}\text { Remuneração do capital } \\
\text { circulante (3\%) }\end{array}$ & $4.465,42$ & 0,03 & 0,01 & 9,42 \\
\hline Sub-Total & & & & \\
\hline Total & $4.465,42$ & 0,03 & 0,01 & 9,42 \\
\hline & $153.312,87$ & $100 \%$ & $42,50 \%$ & 323 \\
\hline & & & \\
\hline
\end{tabular}


BRANCO, J.R.O. et al. Viabilidade técnico-financeira de implantação do sistema de recria/engorda em uma propriedade de cria de bovinos no Município de Uberlândia-MG. PUBVET, Londrina, V. 5, N. 16, Ed. 163, Art. 1101, 2011.

\section{Tabela 9 - Custo de Produção Fixo}

\begin{tabular}{|c|c|c|c|c|}
\hline Especificação & Valor Total & $\begin{array}{l}\text { \% Custo } \\
\text { Fixo }\end{array}$ & $\begin{array}{l}\text { \% Custo } \\
\text { Total }\end{array}$ & $\begin{array}{l}\text { Valor } \\
\text { Unitário }\end{array}$ \\
\hline \multicolumn{5}{|l|}{$\begin{array}{l}\text { CUSTO PRODUÇÃO } \\
\text { FIXO }\end{array}$} \\
\hline \multicolumn{5}{|l|}{$\begin{array}{l}\text { Custo Operacional } \\
\text { fixo }\end{array}$} \\
\hline $\begin{array}{l}\text { Mão-de-obra } \\
\text { permanente }\end{array}$ & $48.086,20$ & 0,23 & 0,13 & 101,44 \\
\hline $\begin{array}{l}\text { Depreciação } \\
\text { máquinas e } \\
\text { equipamentos }\end{array}$ & $3.932,30$ & 0,01 & 0,01 & 8,29 \\
\hline $\begin{array}{l}\text { Depreciação } \\
\text { Instalações }\end{array}$ & 17.838 & 0,08 & 0,05 & 37,63 \\
\hline Sub-Total & $69.856,50$ & 0,33 & 0,19 & 147,37 \\
\hline \multicolumn{5}{|l|}{$\begin{array}{l}\text { Custo Alternativo } \\
\text { Fixo }\end{array}$} \\
\hline $\begin{array}{l}\text { Remuneração } \\
\text { capital fixo }\end{array}$ & $2.590,08$ & 0,01 & 0,007 & 5,46 \\
\hline $\begin{array}{l}\text { Remuneração da } \\
\text { terra }\end{array}$ & 135.000 & 0,65 & 0,37 & 284,81 \\
\hline Sub-Total & $137.590,08$ & 0,66 & 0,38 & 290,27 \\
\hline Total & $207.446,58$ & $100 \%$ & $57,50 \%$ & 437,65 \\
\hline
\end{tabular}

Tabela 10 - Custo de Produção Total

\begin{tabular}{lll}
\hline $\begin{array}{l}\text { Custo Total de } \\
\text { Produção }\end{array}$ & $\begin{array}{l}\% \\
\text { Custo }\end{array}$ \\
\hline Custo Fixo Total & $207.446,58$ & $57,50 \%$ \\
\hline Custo Variável Total & $153.312,87$ & $42,50 \%$ \\
\hline Custo Total & $360.759,45$ & $100 \%$ \\
\hline
\end{tabular}


BRANCO, J.R.O. et al. Viabilidade técnico-financeira de implantação do sistema de recria/engorda em uma propriedade de cria de bovinos no Município de Uberlândia-MG. PUBVET, Londrina, V. 5, N. 16, Ed. 163, Art. 1101, 2011.

Tabela 11 - Apuração dos Resultados da Fazenda Douradinho 2007

\begin{tabular}{lllll}
\hline Especificação & Valor Total & $\begin{array}{l}\text { Valor } \\
\text { Unitário }\end{array}$ & $\begin{array}{l}\% \\
\text { Receita }\end{array}$ & $\begin{array}{l}\% \\
\text { Custo }\end{array}$ \\
\hline RENDA BRUTA & 292.280 & 616,62 & $100 \%$ & x \\
\hline $\begin{array}{l}\text { CUSTO DE } \\
\text { PRODUÇÃo }\end{array}$ & $148.847,45$ & 314,02 & $\mathrm{x}$ & 0,41 \\
\hline $\begin{array}{l}\text { Custo } \\
\text { Operacional } \\
\text { Variável }\end{array}$ & & & & \\
\hline $\begin{array}{l}\text { Custo } \\
\text { Operacional Fixo }\end{array}$ & $69.856,50$ & 147,37 & $\mathrm{x}$ & 0,2 \\
\hline $\begin{array}{l}\text { Custo } \\
\text { Operacional Total }\end{array}$ & $218.703,95$ & 461,4 & $\mathrm{x}$ & 0,6 \\
\hline $\begin{array}{l}\text { Custo Alternativo } \\
\text { Variável }\end{array}$ & $4.465,42$ & 9,42 & $\mathrm{x}$ & 0,01 \\
\hline $\begin{array}{l}\text { Custo Alternativo } \\
\text { Fixo }\end{array}$ & $137.590,08$ & 290,27 & $\mathrm{x}$ & 0,38 \\
\hline $\begin{array}{l}\text { Custo Alternativo } \\
\text { Total }\end{array}$ & $142.055,50$ & 299,69 & $\mathrm{x}$ & 0,3 \\
\hline Custo Total & $360.759,45$ & 761,1 & $\mathrm{x}$ & $100 \%$ \\
\hline $\begin{array}{l}\text { Renda Líquida } \\
\text { (R.B - C.O.T) }\end{array}$ & $73.576,05$ & $\mathrm{x}$ & $\mathrm{x}$ & $\mathrm{x}$ \\
\hline $\begin{array}{l}\text { LUCRO (R.B - } \\
\text { C.T) }\end{array}$ & -68.479 & $\mathrm{x}$ & $\mathrm{x}$ & $\mathrm{x}$ \\
\hline
\end{tabular}

\section{Ponto de Nivelamento}
P.N = Ponto De Nivelamento
C.F.T = Custo Fixo Total
P.u = Preço Unitário
C.V.T.u = Custo Variável Total Unitário
P.N = C.F.T / (P.u - C.V.T.u)
C.F.T $=207.446,58$
P.u $=616,62$
C.V.T.u $=323$

$$
\begin{aligned}
& \text { P.N }=207.446,58 /(616,62-323) \\
& \text { P.N }=\mathbf{7 0 6 . 5 1}
\end{aligned}
$$


BRANCO, J.R.O. et al. Viabilidade técnico-financeira de implantação do sistema de recria/engorda em uma propriedade de cria de bovinos no Município de Uberlândia-MG. PUBVET, Londrina, V. 5, N. 16, Ed. 163, Art. 1101, 2011.

\section{Figura 1 - Gráfico do Ponto de Nivelamento}

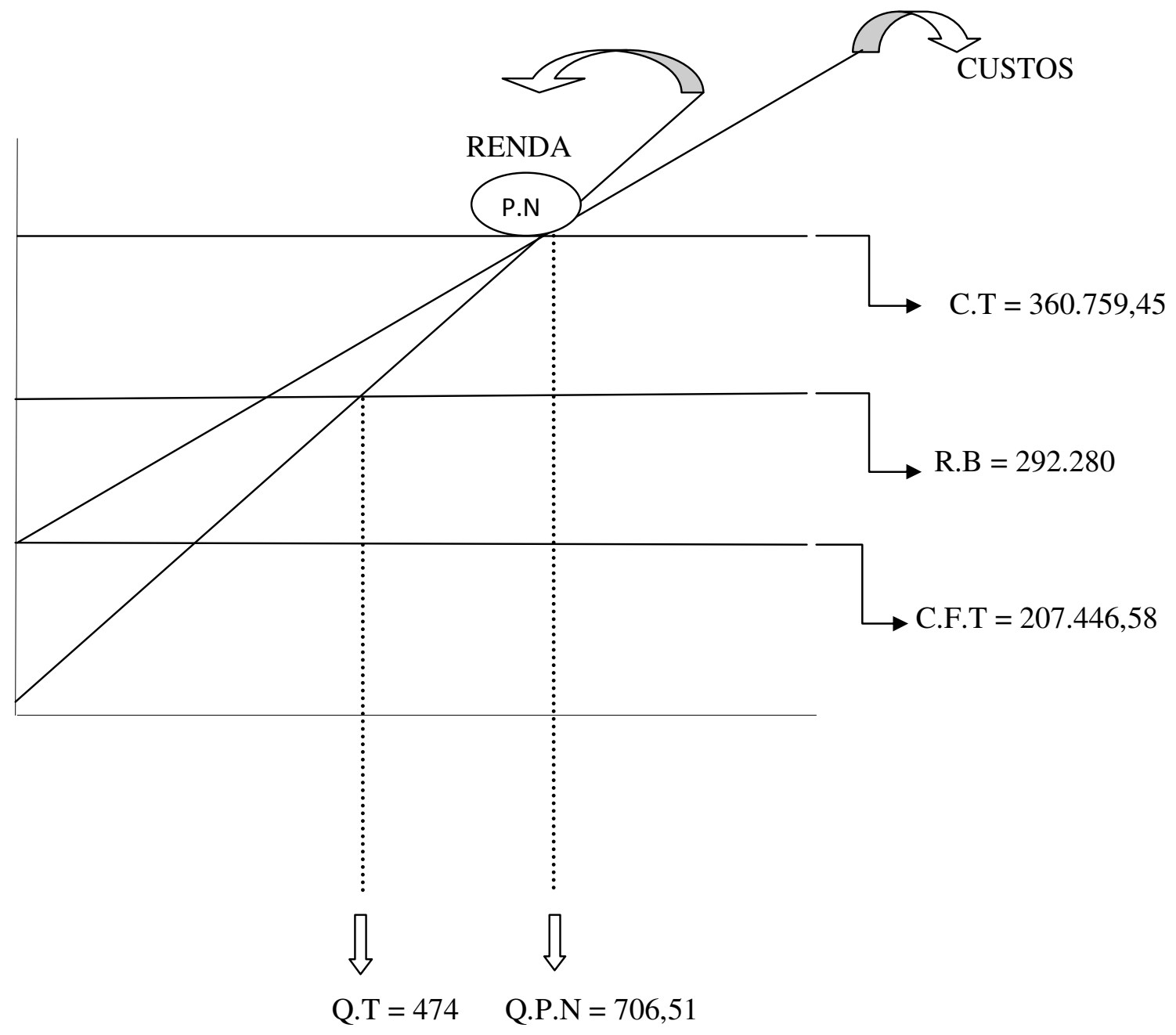

\section{Lucratividade}

A Lucratividade se dá pela subtração do custo total da renda bruta total, multiplicando por cem e dividindo pela renda bruta total.

LUCRATIVIDADE $=\{($ R.B - C.T $) * 100\} /$ R.B

LUCRATIVIDADE $=-23,4$ 
BRANCO, J.R.O. et al. Viabilidade técnico-financeira de implantação do sistema de recria/engorda em uma propriedade de cria de bovinos no Município de Uberlândia-MG. PUBVET, Londrina, V. 5, N. 16, Ed. 163, Art. 1101, 2011.

\section{Capacidade de Investimento}

A Capacidade de Investimento é determinada pela subtração do custo operacional total da renda bruta total, multiplicando por 100 e dividindo pela renda bruta total.

CAP. INVESTIMENTO $=\{($ R.B - C.O.T $) * 100\} /$ R.B

CAP. INVESTIMENTO $=25,17 \%$

\section{Retorno de Investimento}

O Retorno de Investimento é calculado dividindo a renda líquida pelo capital total e multiplicando por 100.

RET. INVESTIMENTO $=($ R.L $/$ C.T $) * 100$

É Renda Líquida: $73.576,05$

É Capital Total:

\begin{tabular}{ll}
\hline Capital Total & Valor $(\mathrm{R} \$)$ \\
\hline Terras & 4.500 .000 \\
\hline $\begin{array}{l}\text { Máquinas e } \\
\text { implementos }\end{array}$ & $69.636,55$ \\
\hline $\begin{array}{l}\text { Construções } \\
\text { e }\end{array}$ & $448.514,98$ \\
Instalações & \\
\hline Insumos & $162.359,31$ \\
\hline Animais & 977.160 \\
\hline Total & $6.157 .670,84$ \\
\hline
\end{tabular}

RET. INVESTIMENTO $=1,19$ 
BRANCO, J.R.O. et al. Viabilidade técnico-financeira de implantação do sistema de recria/engorda em uma propriedade de cria de bovinos no Município de Uberlândia-MG. PUBVET, Londrina, V. 5, N. 16, Ed. 163, Art. 1101, 2011.

\section{Análise de Rentabilidade}

Figura 2 - Gráfico da Análise de Rentabilidade

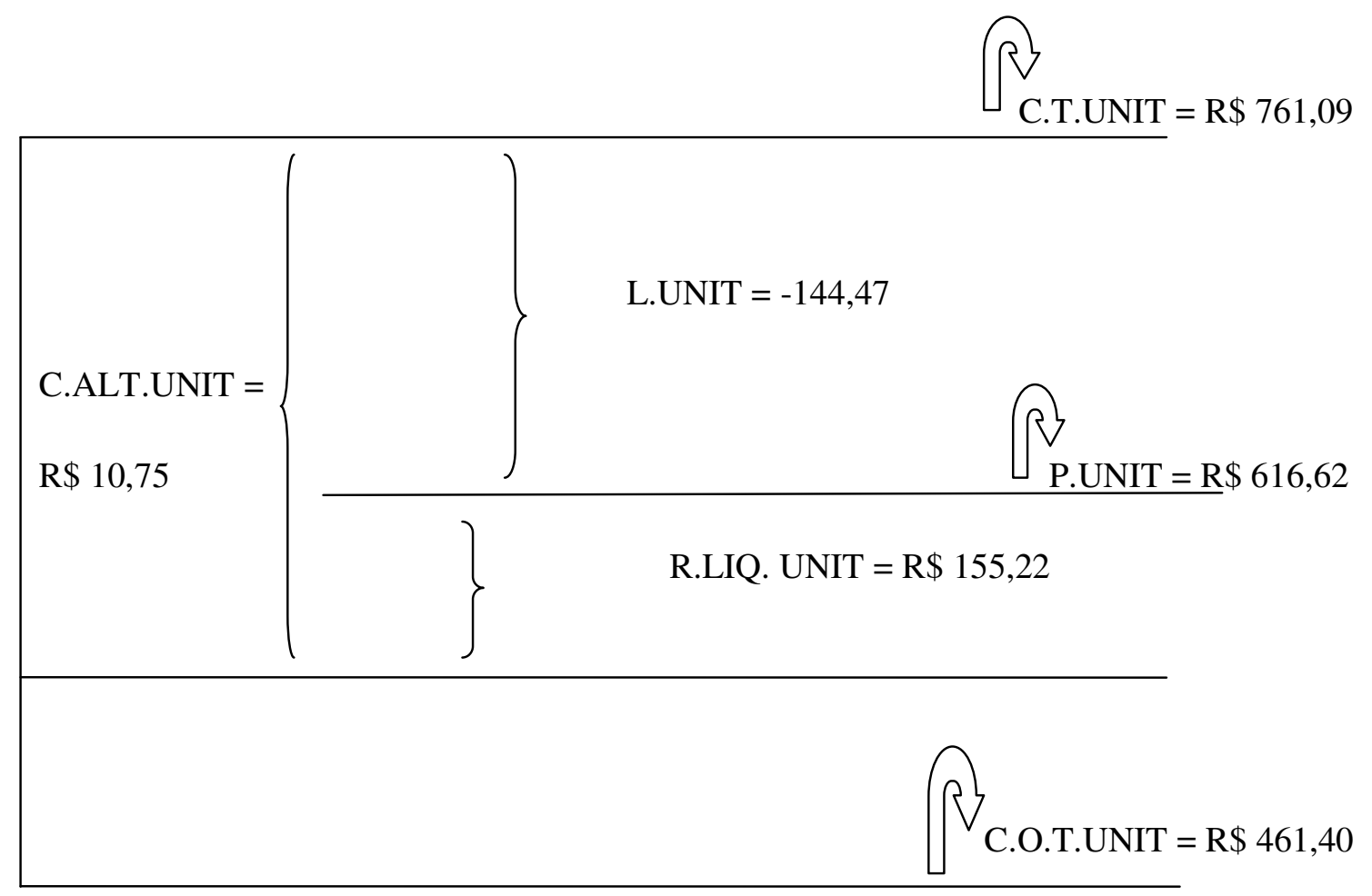

\section{Projeto Agropecuário}

Primeiramente será analisado o método de Recria/Engorda implantado de maneira extensiva. Essa etapa do projeto assume uma característica extrativista e apresenta um quadro que aconteceria caso o produtor simplesmente abrisse mão do método de criação utilizado para implantar de forma irresponsável esse novo sistema de produção envolvendo Cria, Recria e Engorda.

A posteriori será feita uma análise onde o produtor insere de forma efetiva a mudança do método de criação, com investimentos e melhorias. A partir daí poderá ser feita uma análise financeira de ambos os métodos.

O projeto apresenta as variações zootécnicas e financeiras de ambos os métodos (Recria/Engorda extensiva e intensificada) ano a ano. Segundo Pirtousheg (2002), no projeto deve-se trabalhar apenas com valores referentes 
BRANCO, J.R.O. et al. Viabilidade técnico-financeira de implantação do sistema de recria/engorda em uma propriedade de cria de bovinos no Município de Uberlândia-MG. PUBVET, Londrina, V. 5, N. 16, Ed. 163, Art. 1101, 2011.

aos custos operacionais, que são aqueles que envolvem desembolso efetivo. Portanto, não devem ser considerados os valores referentes aos custos alternativos da terra e do capital.

\section{Processo de Produção Recria/Engorda extensiva}

\section{Projeção dos custos, receitas e análise financeira ao longo do projeto}

\section{Quadro 3 - Custos Variáveis}

\begin{tabular}{|c|c|c|c|c|c|c|c|c|c|c|}
\hline Especificação & $1^{0}$ ano & $2^{0}$ ano & $3^{0}$ ano & $4^{0}$ ano & $5^{\circ}$ ano & $6^{0}$ ano & $7^{0}$ ano & $8^{0}$ ano & $9^{\circ}$ ano & $10^{\circ}$ ano \\
\hline $\begin{array}{c}\text { Mão de obra } \\
\text { temporária }\end{array}$ & $3.697,20$ & $3.697,20$ & $3.697,20$ & $3.697,20$ & $3.697,20$ & $3.697,20$ & $3.697,20$ & $3.697,20$ & $3.697,20$ & $3.697,20$ \\
\hline $\begin{array}{c}\text { Manut. de } \\
\text { Máq. e Equip. }\end{array}$ & $4.284,00$ & $4.284,00$ & $4.284,00$ & $4.284,00$ & $4.284,00$ & $4.284,00$ & $4.284,00$ & $4.284,00$ & $4.284,00$ & $4.284,00$ \\
\hline $\begin{array}{c}\text { Manut. de } \\
\text { Instalações }\end{array}$ & 11.892 & 11.892 & 11.892 & 11.892 & 11.892 & 11.892 & 11.892 & 11.892 & 11.892 & 11.892 \\
\hline Sal Mineral & 11.764 & $15.423,30$ & $19.529,10$ & $19.529,10$ & $19.529,10$ & $19.529,10$ & $19.529,10$ & $19.529,10$ & $19.529,10$ & $19.529,10$ \\
\hline Sal & $50.573,25$ & $66.303,90$ & $83.555,55$ & $83.555,55$ & $83.555,55$ & $83.555,55$ & $83.555,55$ & $83.555,55$ & $83.555,55$ & $83.555,55$ \\
\hline Silagem milho & $22.274,00$ & 178.030 & 362.586 & 362.586 & 362.586 & 362.586 & 362.586 & 362.586 & 362.586 & 362.586 \\
\hline Energia & 21.000 & 21.000 & 21.000 & 21.000 & 21.000 & 21.000 & 21.000 & 21.000 & 21.000 & 21.000 \\
\hline Combustível & 9.125 & 9.125 & 9.125 & 9.125 & 9.125 & 9.125 & 9.125 & 9.125 & 9.125 & 9.125 \\
\hline Telefone & 3.600 & 3.600 & 3.600 & 3.600 & 3.600 & 3.600 & 3.600 & 3.600 & 3.600 & 3.600 \\
\hline Vacinação & $4.087,00$ & $4.820,20$ & $5.390,30$ & $5.390,30$ & $5.390,30$ & $5.390,30$ & $5.390,30$ & $5.390,30$ & $5.390,30$ & $5.390,30$ \\
\hline Vermifugação & 550 & 770 & 990 & 990 & 990 & 990 & 990 & 990 & 990 & 990 \\
\hline Medicamentos & 6.000 & 8.000 & 12.000 & 12.000 & 12.000 & 12.000 & 12.000 & 12.000 & 12.000 & 12.000 \\
\hline Total & $148.846,45$ & $326.945,60$ & $537.649,15$ & $537.649,15$ & $537.649,15$ & $537.649,15$ & $537.649,15$ & $537.649,15$ & $537.649,15$ & $537.649,15$ \\
\hline
\end{tabular}

\section{Quadro 4 - Custos Fixos}

\begin{tabular}{|c|c|c|c|c|c|c|c|c|c|c|}
\hline Especificação & $1^{\circ}$ ano & $2^{\circ}$ ano & $3^{\circ}$ ano & $4^{\circ}$ ano & $5^{\circ}$ ano & $6^{\circ}$ ano & $7^{\circ}$ ano & $8^{\circ}$ ano & $9^{\circ}$ ano & $10^{\circ}$ ano \\
\hline $\begin{array}{c}\text { Mão de Obra } \\
\text { permanente }\end{array}$ & $48.086,20$ & $48.086,20$ & $48.086,20$ & $48.086,20$ & $48.086,20$ & $48.086,20$ & $48.086,20$ & $48.086,20$ & $48.086,20$ & $48.086,20$ \\
\hline $\begin{array}{c}\text { Deprec.Máq. } \\
\text { e Equip. }\end{array}$ & $3.932,30$ & $3.932,30$ & $3.932,30$ & $3.932,30$ & $3.932,30$ & $3.932,30$ & $3.932,30$ & $3.932,30$ & $3.932,30$ & $3.932,30$ \\
\hline $\begin{array}{c}\text { Deprec. } \\
\text { Instalações }\end{array}$ & 17.838 & 17.838 & 17.838 & 17.838 & 17.838 & 17.838 & 17.838 & 17.838 & 17.838 & 17.838 \\
\hline Total & $69.856,50$ & $69.856,50$ & $69.856,50$ & $69.856,50$ & $69.856,50$ & $69.856,50$ & $69.856,50$ & $69.856,50$ & $69.856,50$ & $69.856,50$ \\
\hline
\end{tabular}

\section{Quadro 5 - Receitas}

\begin{tabular}{|c|c|c|c|c|c|c|c|c|c|c|}
\hline Especificaçã & $1^{0}$ ano & $2^{0}$ ano & $3^{0}$ ano & $4^{0}$ ano & $5^{0}$ ano & $6^{0}$ ano & $7^{0}$ ano & $8^{0}$ ano & $9^{0}$ ano & $10^{0}$ ano \\
\hline $\begin{array}{c}\text { Venda de } \\
\text { animais }\end{array}$ & 91.070 & 188.010 & $513.202,32$ & $513.202,32$ & $513.202,32$ & $513.202,32$ & $513.202,32$ & $513.202,32$ & $513.202,32$ & $513.202,32$ \\
\hline Total & 91.070 & 188.010 & $513.202,32$ & $513.202,32$ & $513.202,32$ & $513.202,32$ & $513.202,32$ & $513.202,32$ & $513.202,32$ & $513.202,32$ \\
\hline
\end{tabular}


BRANCO, J.R.O. et al. Viabilidade técnico-financeira de implantação do sistema de recria/engorda em uma propriedade de cria de bovinos no Município de Uberlândia-MG.

PUBVET, Londrina, V. 5, N. 16, Ed. 163, Art. 1101, 2011.

\section{Quadro 6 - Análise financeira}

\begin{tabular}{|c|c|c|c|c|c|c|c|c|c|c|}
\hline \begin{tabular}{|l|} 
Especificação \\
\end{tabular} & $1^{\circ}$ ano & $2^{\circ}$ ano & $3^{\circ}$ ano & $4^{\circ}$ ano & $5^{\circ}$ ano & $6^{\circ}$ ano & $7^{0}$ ano & $8^{\circ}$ ano & $9^{\circ}$ ano & $10^{\circ}$ ano \\
\hline \multicolumn{11}{|l|}{ Entradas } \\
\hline $\begin{array}{l}\text { Venda de } \\
\text { Animais }\end{array}$ & 91.070 & 188.010 & $513.202,32$ & $513.202,32$ & $513.202,32$ & $513.202,32$ & $513.202,32$ & $513.202,32$ & $513.202,32$ & $513.202,32$ \\
\hline Finan. & $127.632,95$ & $208.792,10$ & & & & & & & & \\
\hline \begin{tabular}{|l|} 
Rec. Próprios \\
\end{tabular} & & & 618,83 & & & & & & & \\
\hline Total & $218.702,95$ & 396802,1 & $513.821,15$ & $513.202,32$ & $513.202,32$ & $513.202,32$ & $513.202,32$ & $513.202,32$ & $513.202,32$ & $513,202,32$ \\
\hline \multicolumn{11}{|l|}{ Saídas } \\
\hline Investim & & & $42.720,50$ & & & & & & & \\
\hline Ctos Variáveis & $148.846,45$ & $326.945,60$ & $367.572,35$ & $537.649,15$ & $537.649,15$ & $537.649,15$ & $537.649,15$ & $537.649,15$ & $537.649,15$ & $537.649,15$ \\
\hline Ctos Fixos & $69.856,50$ & $69.856,50$ & $80.575,30$ & $80.575,30$ & $80.575,30$ & $80.575,30$ & $80.575,30$ & $80.575,30$ & $80.575,30$ & $80.575,30$ \\
\hline Amort. Finan. & & & $21.272,00$ & $56.070,00$ & $56.070,00$ & $56.070,00$ & $56.070,00$ & $56.070,00$ & $56.070,00$ & \\
\hline Juros & & & $1.681,00$ & $4.725,00$ & $4.725,00$ & $4.725,00$ & $4.725,00$ & $4.725,00$ & $4.725,00$ & \\
\hline Total & $218.702,95$ & $396.802,10$ & $513.821,15$ & $679.019,45$ & $679.019,45$ & $679.019,45$ & $679.019,45$ & $679.019,45$ & $679.019,45$ & $618.224,45$ \\
\hline Saldo & 0,00 & 0,00 & 0,00 & $-165.817,13$ & $-165.817,13$ & $-165.817,13$ & $-165.817,13$ & $-165.817,13$ & $-165.817,13$ & $-105.022,13$ \\
\hline \begin{tabular}{|l|} 
Saldo acum. \\
\end{tabular} & & & & $-165.817,13$ & $-331.634,26$ & $-497.451,39$ & $-663.268,52$ & $-829.085,65$ & $-994.902,78$ & $-1.099,924,91$ \\
\hline
\end{tabular}

A projeção mostra uma Inviabilidade financeira evidente no método. Fazse desnecessário o levantamento do desempenho pós projeto afim de comparações, uma vez que por si só a atividade se tornaria inviável.

\section{Processo de Produção Recria Engorda Intensiva}

\section{Projeção dos custos, receitas e análise financeira ao longo do projeto}

\section{Quadro 7 - Custo variável}

\begin{tabular}{|c|c|c|c|c|c|c|c|c|c|c|}
\hline Especificação & $1^{\mathrm{o}}$ ano & $2^{\mathrm{o}}$ ano & $3^{\mathrm{o}}$ ano & $4^{\mathrm{o}}$ ano & $5^{\circ}$ ano & $6^{\mathrm{o}}$ ano & $7^{\mathrm{o}}$ ano & $8^{\circ}$ ano & $9^{\circ}$ ano & $10^{\circ}$ ano \\
\hline $\begin{array}{c}\text { Mão de obra } \\
\text { temporária }\end{array}$ & $5.000,00$ & $7.249,40$ & $7.249,40$ & $7.249,40$ & $7.249,40$ & $4.249,40$ & $4.249,40$ & $4.249,40$ & $4.249,40$ & $4.249,40$ \\
\hline $\begin{array}{c}\text { Manut. de } \\
\text { Máq. e Equip. }\end{array}$ & $4.284,00$ & $4.284,00$ & $4.284,00$ & $4.284,00$ & $4.284,00$ & $4.284,00$ & $4.284,00$ & $4.284,00$ & $4.284,00$ & $4.284,00$ \\
\hline $\begin{array}{c}\text { Manut. de } \\
\text { Instalaçães }\end{array}$ & 11.892 & 11.892 & 11.892 & 11.892 & 11.892 & 11.892 & 11.892 & 11.892 & 11.892 & 11.892 \\
\hline Sal Mineral & $11.764,00$ & $15.423,30$ & $19.529,10$ & $19.529,10$ & $19.529,10$ & $19.529,10$ & $19.529,10$ & $19.529,10$ & $19.529,10$ & $19.529,10$ \\
\hline Sal Proteinado & $50.573,25$ & $66.303,90$ & $83.555,55$ & $83.555,55$ & $83.555,55$ & $83.555,55$ & $83.555,55$ & $83.555,55$ & $83.555,55$ & $83.555,55$ \\
\hline Silagem milho & & 66.444 & 188.957 & 145.759 & 51.664 & 118.219 & 118.219 & 118.219 & 118.219 & 118.219 \\
\hline Energia & 21.000 & 21.000 & 21.000 & 21.000 & 21.000 & 21.000 & 21.000 & 21.000 & 21.000 & 21.000 \\
\hline Combustível & 9.125 & 9.125 & 9.125 & 9.125 & 9.125 & 9.125 & 9.125 & 9.125 & 9.125 & 9.125 \\
\hline Telefone & 3.600 & 3.600 & 3.600 & 3.600 & 3.600 & 3.600 & 3.600 & 3.600 & 3.600 & 3.600 \\
\hline Vacinação & $4.087,00$ & $4.820,20$ & $5.390,30$ & $5.390,30$ & $5.390,30$ & $5.390,30$ & $5.390,30$ & $5.390,30$ & $5.390,30$ & $5.390,30$ \\
\hline Vermifugação & 550 & 770 & 990 & 990 & 990 & 990 & 990 & 990 & 990 & 990 \\
\hline Medicamentos & 6.000 & 8.000 & 12.000 & 12.000 & 12.000 & 12.000 & 12.000 & 12.000 & 12.000 & 12.000 \\
\hline Total & $127.875,25$ & $218.911,80$ & $367.572,35$ & $324.374,35$ & $230.279,35$ & $293.834,35$ & $293.834,35$ & $293.834,35$ & $293.834,35$ & $293.834,35$ \\
\hline
\end{tabular}


BRANCO, J.R.O. et al. Viabilidade técnico-financeira de implantação do sistema de recria/engorda em uma propriedade de cria de bovinos no Município de Uberlândia-MG.

PUBVET, Londrina, V. 5, N. 16, Ed. 163, Art. 1101, 2011.

\section{Quadro 8 - Custo Fixo}

\begin{tabular}{|c|c|c|c|c|c|c|c|c|c|c|}
\hline Especificação & $1^{\circ}$ ano & $2^{\circ}$ ano & $3^{\circ}$ ano & $4^{\circ}$ ano & $5^{\circ}$ ano & $6^{\circ}$ ano & $7^{\circ}$ ano & $8^{\circ}$ ano & $9^{\circ}$ ano & $10^{\circ}$ ano \\
\hline $\begin{array}{c}\text { Mão de Obra } \\
\text { permanente }\end{array}$ & $48.086,20$ & $48.086,20$ & $58.805,00$ & $58.805,00$ & $58.805,00$ & $58.805,00$ & $58.805,00$ & $58.805,00$ & $58.805,00$ & $58.805,00$ \\
\hline $\begin{array}{c}\text { Deprec.Máq. e } \\
\text { Equip. }\end{array}$ & $3.932,30$ & $3.932,30$ & $3.932,30$ & $3.932,30$ & $3.932,30$ & $3.932,30$ & $3.932,30$ & $3.932,30$ & $3.932,30$ & $3.932,30$ \\
\hline $\begin{array}{c}\text { Deprec. } \\
\text { Instalações }\end{array}$ & 17.838 & 17.838 & 17.838 & 17.838 & 17.838 & 17.838 & 17.838 & 17.838 & 17.838 & 17.838 \\
\hline Total & $69.856,50$ & $69.856,50$ & $80.575,30$ & $80.575,30$ & $80.575,30$ & $80.575,30$ & $80.575,30$ & $80.575,30$ & $80.575,30$ & $80.575,30$ \\
\hline
\end{tabular}

\section{Quadro 9 - Receitas}

\begin{tabular}{|c|c|c|c|c|c|c|c|c|c|c|}
\hline Especificação & $1^{0}$ ano & $2^{0}$ ano & $3^{0}$ ano & $4^{0}$ ano & $5^{0}$ ano & $6^{0}$ ano & $7^{0}$ ano & $8^{0}$ ano & $9^{0}$ ano & $10^{0}$ ano \\
\hline $\begin{array}{c}\text { Venda de } \\
\text { animais }\end{array}$ & 91.070 & 188.010 & $513.202,32$ & $513.202,32$ & $513.202,32$ & $513.202,32$ & $513.202,32$ & $513.202,32$ & $513.202,32$ & $513.202,32$ \\
\hline Total & 91.070 & 188.010 & $513.202,32$ & $513.202,32$ & $513.202,32$ & $513.202,32$ & $513.202,32$ & $513.202,32$ & $513.202,32$ & $513.202,32$ \\
\hline
\end{tabular}

\section{Quadro 10 - Análise Financeira}

\begin{tabular}{|c|c|c|c|c|c|c|c|c|c|c|}
\hline Especificação & $1^{\circ}$ ano & $2^{\circ}$ ano & $3^{\circ}$ ano & $4^{\circ}$ ano & $5^{\circ}$ ano & $6^{\circ}$ ano & $7^{\circ}$ ano & $8^{\circ}$ ano & $9^{\circ}$ ano & $10^{\circ}$ ano \\
\hline \multicolumn{11}{|l|}{ Entradas } \\
\hline $\begin{array}{l}\text { Venda de } \\
\text { Animais }\end{array}$ & 91.070 & 188.010 & $513.202,32$ & $513.202,32$ & $513.202,32$ & $513.202,32$ & $513.202,32$ & $513.202,32$ & $513.202,32$ & $513.202,32$ \\
\hline Finan. & $.583,61$ & 150367,26 & $38.738,16$ & & & & & & & \\
\hline Rec. Próprios & & & & 434,62 & & & & & & \\
\hline Total & $277.653,61$ & 338377,26 & $551.940,48$ & $513.636,94$ & $513.202,32$ & $513.202,32$ & $513.202,32$ & $513.202,32$ & $513.202,32$ & $513.202,32$ \\
\hline \multicolumn{11}{|l|}{ Saídas } \\
\hline Investim & $79.921,86$ & $49.608,96$ & $42.720,50$ & 39.220 & $26.391,35$ & $38.163,69$ & 37.212 & 37.212 & 37.212 & \\
\hline Ctos Variáveis & $127.875,25$ & $218.911,80$ & $367.572,35$ & $324.374,30$ & $230.279,35$ & $293.834,35$ & $293.834,35$ & \begin{tabular}{|l|}
$293.834,35$ \\
\end{tabular} & $293.834,35$ & $332.128,39$ \\
\hline Ctos Fixos & $69.856,50$ & $69.856,50$ & $80.575,30$ & $80.575,30$ & $80.575,30$ & $80.575,30$ & $80.575,30$ & $80.575,30$ & $80.575,30$ & $84.743,50$ \\
\hline Amort. Finan. & & & $56.158,47$ & $63.878,02$ & 63.878,02 & $63.878,02$ & $63.878,02$ & \begin{tabular}{|l|}
$63.878,02$ \\
\end{tabular} & $63.878,02$ & \\
\hline Juros & & & $4.913,86$ & $5.589,32$ & $5.589,32$ & $5.589,32$ & $5.589,32$ & $5.589,32$ & $5.589,32$ & \\
\hline Total & $277.653,61$ & $338.377,26$ & $551.940,48$ & $513.636,94$ & $406.713,34$ & $482.040,68$ & $481.088,99$ & \begin{tabular}{|l|}
$481.088,99$ \\
\end{tabular} & $481.088,99$ & $416.871,89$ \\
\hline Saldo & 0,00 & 0,00 & 0,00 & 0,00 & $106.488,98$ & \begin{tabular}{|l|}
$31.161,64$ \\
\end{tabular} & $32.113,33$ & \begin{tabular}{|l|}
$32.113,33$ \\
\end{tabular} & $32.113,33$ & $96.330,43$ \\
\hline Saldo acum. & & & & 0,00 & $106.488,98$ & $137.650,62$ & $169.763,95$ & \begin{tabular}{|l|}
$201.877,28$ \\
\end{tabular} & $233.990,61$ & $330.321,04$ \\
\hline
\end{tabular}

Para fins de comparação será feito um levantamento do desempenho do método de Recria/Engorda tendo como base os valores obtidos no $10^{\circ}$ ano, já que a partir dele existe uma constância tanto na movimentação do rebanho com nos investimentos. A partir dele os investimentos que acontecem são referentes ao processo de adubação, sendo assim, passa a ser incorporado nos custos variáveis. 
BRANCO, J.R.O. et al. Viabilidade técnico-financeira de implantação do sistema de recria/engorda em uma propriedade de cria de bovinos no Município de Uberlândia-MG. PUBVET, Londrina, V. 5, N. 16, Ed. 163, Art. 1101, 2011.

Será considerado que o sistema teria sido implantado 10 anos atrás, sendo desnecessárias estimas sobre os preços de insumos, valor da terra, preços de equipamentos e instalações assim como suas respectivas depreciações em 2017/2018. No entanto, algumas mudanças acontecerão em função de novos insumos (Calcário Dolomítico, Gesso Agrícola, Adubo npk 1010-10) e instalações (piquetes). Abaixo seguem as alterações e o desempenho econômico que o método apresentaria em 2007 caso tivesse sido implantado.

\section{Desempenho Econômico na Fazenda Douradinho no Sistema}

\section{Cria/Recria/Engorda}

\section{Inventário da Propriedade}

Tabela 12 - Uso Atual e Valor da Terra

\begin{tabular}{lll}
\hline Uso atual & Área (ha) & Valor $(\mathrm{R} \$)$ \\
\hline Pastagens & Próprias & Próprias \\
\hline Reservas & 600 & $3.375 .000,00$ \\
\hline Área Preservação Permanente & 15 & $984.375,00$ \\
\hline Instalações & 25 & $84.375,00$ \\
\hline Total & 800 & $140.625,00$ \\
\hline Remuneração da terra 3\% & - & $4.500 .000,00$ \\
\hline & & $135.000,00$ \\
\hline
\end{tabular}

\section{Equipamentos}

Trator MASSEY FERGUSON 200280 H.P

Ensiladeira TRAPP 20043 H.P

Triturador Forrageiro TRAPP 2002 3,5 H.P

Grade Aradora (24 discos 26") BALDAN 2004

Grade Niveladora (42 discos 20") BALDAN 2004

Roçadeira TATU MARCHESAN 200270 H.P

Carreta Graneleira RANDON 1999

$\begin{array}{ll}\text { Horas de Uso / } & \text { Manutenção (ano) } \\ 1000 & 5 \% \\ 360 & 3 \% \\ 360 & 5 \% \\ 1000 & 5 \% \\ 1000 & 5 \% \\ 700 & 5 \% \\ 500 & 5 \%\end{array}$


BRANCO, J.R.O. et al. Viabilidade técnico-financeira de implantação do sistema de recria/engorda em uma propriedade de cria de bovinos no Município de Uberlândia-MG. PUBVET, Londrina, V. 5, N. 16, Ed. 163, Art. 1101, 2011.

\section{Quadro 12 - Depreciação de máquinas e equipamentos}

\begin{tabular}{|c|c|c|c|c|c|c|c|c|c|c|}
\hline Especificação & $\mathrm{N}^{0} . \mathrm{HP}$ & Quant. & $\begin{array}{l}\text { Ano de } \\
\text { fabric. }\end{array}$ & Vida Útil & Idade & Valor Atual & $\begin{array}{c}\text { Valor } \\
\text { Inicial }\end{array}$ & $\begin{array}{c}\text { Valor } \\
\text { Residual }\end{array}$ & Manut. & $\begin{array}{r}\text { Deprec. } \\
\text { Anual }\end{array}$ \\
\hline Trator & 80 & 1 & 2002 & 25 & 5 & 32.000 & 40.000 & 4.000 & 2.000 & 1.800 \\
\hline \begin{tabular}{|l|} 
Ensiladeira \\
\end{tabular} & 3 & 1 & 2004 & 13 & 3 & $4.230,00$ & 5.500 & 550 & 165 & 495 \\
\hline Triturador & 3,5 & 1 & 2002 & 25 & 5 & $1.148,80$ & 1.436 & 143,6 & 71,8 & 64,62 \\
\hline $\begin{array}{c}\text { Grade } \\
\text { Aradora }\end{array}$ & & 1 & 2004 & 23 & 3 & $8.226,08$ & 9.460 & 946 & 473 & 425,7 \\
\hline \begin{tabular}{|c|} 
Grade \\
Niveladora
\end{tabular} & & 1 & 2004 & 23 & 3 & $5.217,39$ & 6.000 & 600 & 300 & 270 \\
\hline Roçadeira & 70 & 1 & 2002 & 25 & 5 & 5.600 & 7.000 & 700 & 350 & 315 \\
\hline $\begin{array}{c}\text { Carreta } \\
\text { Graneleira }\end{array}$ & & 1 & 1999 & 28 & 8 & $13.214,28$ & 18.500 & 1850 & 925 & 832,5 \\
\hline Total & & 7 & & & & 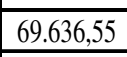 & 87.896 & $8.789,60$ & $4.284,80$ & $\begin{array}{r}3.932,30 \\
\end{array}$ \\
\hline $\begin{array}{l}\text { Remuneração } \\
\text { do capital 6\% }\end{array}$ & & & & & & 4.178 & 5.273 & 527,3 & 257,088 & 235,9 \\
\hline
\end{tabular}

Instalações (Manutenção anual de 2 a 2,5\%, com uma média de 2,25\% em todas as instalações)

Curral Manejo 2002 (Inclui Brete, embarcadouro, cercas e corredores de aroeira com 10 de espaçamento entre os postes)

Barracão 2002

Casa-sede 1997

Casa-peão 2002

Retiro 1997

Balança 2007

Piquetes (arame + moirões) "1997" 
BRANCO, J.R.O. et al. Viabilidade técnico-financeira de implantação do sistema de recria/engorda em uma propriedade de cria de bovinos no Município de Uberlândia-MG. PUBVET, Londrina, V. 5, N. 16, Ed. 163, Art. 1101, 2011.

\section{Quadro 13 - Depreciação das instalações}

\begin{tabular}{|l|l|l|l|l|l|l|l|l|l|}
\hline Descrição & Dimensão & $\begin{array}{l}\text { Ano } \\
\text { construção }\end{array}$ & Vida Útil & Idade & Valor Atual & $\begin{array}{l}\text { Valor } \\
\text { Inicial }\end{array}$ & $\begin{array}{l}\text { Valor } \\
\text { Residual }\end{array}$ & Manut & Deprec. \\
\hline $\begin{array}{l}\text { Currais de } \\
\text { Manejo }\end{array}$ & $20 \times 15$ & 2002 & 35 & 5 & $308.571,42$ & 360.000 & 36.000 & 8.000 & 12.000 \\
\hline Barracão & $10 \times 20$ & 2002 & 35 & 5 & $19.285,71$ & 22.500 & 2.500 & 500 & 750 \\
\hline Casa-sede & $15 \times 15$ & 1997 & 40 & 10 & 33.750 & 45.000 & 4.500 & 1.000 & 1.500 \\
\hline Casa-paão & $15 \times 10$ & 2002 & 35 & 5 & $23.142,85$ & 27.000 & 2.700 & 600 & 900 \\
\hline Retiro & $20 x 15$ & 1997 & 40 & 10 & 50.625 & 67.500 & 6.750 & 1.500 & 2.250 \\
\hline Piquetes & & 1997 & 20 & 10 & 24.343 & 48.686 & 4.868 & $1.081,90$ & 4.868 \\
\hline Balança & $4 \times 2,5$ & 2007 & 30 & 0 & 13.140 & 13.140 & 1.340 & 292 & 438 \\
\hline Total & & & & & $472.857,98$ & 583.826 & 58.382 & $12.973,90$ & $22.706,60$ \\
\hline $\begin{array}{l}\text { Rem. } \\
\text { capital 6\% }\end{array}$ & & & & & $28.371,47$ & $35.029,50$ & $3.502,90$ & 778,43 & $1.362,40$ \\
\hline
\end{tabular}

\section{Insumos}

Dentre os insumos estão: Sal mineral NUTANE, Sal proteinado NUTANE, Silagem de milho, Calcário, Gesso agrícola, Adubo npk 10-10-10, Energia, Combustível, Telefone, Vacina Febra Aftosa MERIAL, Vacina Brucelose MERIAL, Vacina Raiva MERIAL, Vacina Manqueira (Carbúnculo Sintomático) MERIAL, Vacina Botulismo MERIAL, Vermífugo NOVARTIS.

Vacina Febre Aftosa - Maio (rebanho inteiro) $=1.834$ animais. $(1.814+20$ animais mortos)

Novembro (até 24 meses) $=959$ animais.

Total: 2.793 doses.

Vacina Brucelose - (fêmeas 3 a 8 meses) $=235$ animais.

Total: 235 doses.

Vacina Raiva $-($ rebanho inteiro $)=1.834$ animais.

Total: 1.834 doses.

Vacina Carbúnculo Sintomático (Manqueira) - (rebanho inteiro) $=1.834$ animais.

Total: 1.834 doses.

Vacina Botulismo $-($ rebanho inteiro $)=1.834$ animais.

Total: 1.834 doses. 
BRANCO, J.R.O. et al. Viabilidade técnico-financeira de implantação do sistema de recria/engorda em uma propriedade de cria de bovinos no Município de Uberlândia-MG. PUBVET, Londrina, V. 5, N. 16, Ed. 163, Art. 1101, 2011.

Vermífugação - 3 x ao ano (Maio/Julho/Setembro) no rebanho inteiro.

São administrados $2 \mathrm{ml}$ por U.A em cada vermifugação. Totaliza-se um total de 2,85 litros em cada etapa. Anualmente administra-se 9 litros no rebanho.

Tabela 13 - Insumos consumidos

\begin{tabular}{|c|c|c|c|c|c|}
\hline $\begin{array}{l}\text { Tipos de } \\
\text { Insumos }\end{array}$ & Unidade & $\begin{array}{l}\text { Quantidade } \\
\text { (dia) }\end{array}$ & $\begin{array}{l}\text { Quantidade } \\
\text { (180 dias) }\end{array}$ & $\begin{array}{l}\text { Valor } \\
\text { Unitário }\end{array}$ & Valor Total \\
\hline Sal Mineral & $\begin{array}{l}\text { 70g/U.A/dia } \\
\text { (águas) }\end{array}$ & $\begin{array}{l}100,4 \\
\mathrm{~kg} / \mathrm{dia}\end{array}$ & $\begin{array}{l}18.082,5 \mathrm{~kg} / \\
180 \text { dias }\end{array}$ & $\mathrm{R} \$ 1,08 / \mathrm{kg}$ & $\begin{array}{l}\mathrm{R} \$ \\
19.529,1\end{array}$ \\
\hline \multirow[t]{2}{*}{ Sal Proteinado } & $\begin{array}{l}\text { 250g/U.A/dia } \\
\text { (seca) }\end{array}$ & $\begin{array}{l}357,07 \\
\mathrm{~kg} / \mathrm{dia}\end{array}$ & $\begin{array}{l}\mathrm{kg} / \\
180 \text { dias }\end{array}$ & $\mathrm{R} \$ 1,30 / \mathrm{kg}$ & $\begin{array}{l}\text { R\$ } \\
83.555,55\end{array}$ \\
\hline & & & $\begin{array}{l}\text { Quantidade } \\
\text { (365 dias) }\end{array}$ & & \\
\hline $\begin{array}{l}\text { Silagem milho } \\
\text { (M.S) }\end{array}$ & $\mathrm{kg} / \mathrm{U} . \mathrm{A}$ & $\mathrm{kg} / \mathrm{dia}$ & $\begin{array}{l}2.246 .534 \\
\mathrm{~kg} / \mathrm{ano}\end{array}$ & $\mathrm{R} \$ 90 / \mathrm{t}$ & $\begin{array}{l}\mathrm{R} \$ \\
118.219,14\end{array}$ \\
\hline Calcário & t/ha & - & 240.000 & $\mathrm{R} \$ 20,00 / \mathrm{t}$ & $R \$ 4.800$ \\
\hline Gesso & t/ha & - & 60.000 & $\mathrm{R} \$ 28,00 / \mathrm{t}$ & $R \$ 1.680$ \\
\hline Adubo & t/ha & - & 24.000 & $\mathrm{R} \$ 808,00 / \mathrm{t}$ & $R \$ 19.392$ \\
\hline Energia & $\mathrm{KW} / \mathrm{mês}$ & - & - & $\begin{array}{l}\mathrm{R} \$ \\
1.750 / \mathrm{mês}\end{array}$ & $\begin{array}{l}\mathrm{R} \$ \\
21.000\end{array}$ \\
\hline Combustível & Litros/dia & 10 litros/dia & $\begin{array}{l}3.650 \\
\text { Litros/ano }\end{array}$ & $\begin{array}{l}\mathrm{R} \$ \\
2,50 / \text { litro }\end{array}$ & $\begin{array}{l}\mathrm{R} \$ \\
9.125\end{array}$ \\
\hline Telefone & - & - & - & - & $\begin{array}{l}\mathrm{R} \$ \\
3.600\end{array}$ \\
\hline $\begin{array}{l}\text { Vacina Febre } \\
\text { Aftosa }\end{array}$ & Dose/animal & & $\begin{array}{l}2.793 \\
\text { Doses/ano }\end{array}$ & $\begin{array}{l}\mathrm{R} \$ \\
1,10 / \text { dose }\end{array}$ & $\begin{array}{l}\mathrm{R} \$ \\
3.072,30\end{array}$ \\
\hline $\begin{array}{l}\text { Vacina } \\
\text { Brucelose }\end{array}$ & Dose/animal & & $\begin{array}{l}235 \\
\text { Doses/ano }\end{array}$ & $\begin{array}{l}\mathrm{R} \$ \\
0,50 / \text { dose }\end{array}$ & $\begin{array}{l}\mathrm{R} \$ \\
117,5\end{array}$ \\
\hline Vacina Raiva & Dose/animal & & $\begin{array}{l}1.834 \\
\text { Doses/ano }\end{array}$ & $\begin{array}{l}\mathrm{R} \$ \\
0,30 / \text { dose }\end{array}$ & $\begin{array}{l}R \$ \\
550,20\end{array}$ \\
\hline $\begin{array}{l}\text { Vacina } \\
\text { Manqueira }\end{array}$ & Dose/animal & & $\begin{array}{l}1.834 \\
\text { Doses /ano }\end{array}$ & $\begin{array}{l}\mathrm{R} \$ \\
0,50 / \text { dose }\end{array}$ & $\begin{array}{l}\mathrm{R} \$ \\
917,00\end{array}$ \\
\hline $\begin{array}{l}\text { Vacina } \\
\text { Botulismo }\end{array}$ & Dose/animal & & $\begin{array}{l}1.834 \\
\text { Doses/ano }\end{array}$ & $\begin{array}{l}\mathrm{R} \$ \\
0,40 / \text { dose }\end{array}$ & $\begin{array}{l}R \$ \\
733,60\end{array}$ \\
\hline Vermífugo & $\begin{array}{l}\text { Litros } \\
\text { (ml/animal) }\end{array}$ & & $\begin{array}{l}09 \\
\text { Litros/ano }\end{array}$ & $\begin{array}{l}\mathrm{R} \$ \\
110,00 / \text { litro }\end{array}$ & $\begin{array}{l}\mathrm{R} \$ \\
990,00\end{array}$ \\
\hline $\begin{array}{l}\text { Medicamentos } \\
\text { (vários) }\end{array}$ & $\begin{array}{l}\text { Litros } \\
\text { (ml/animal) }\end{array}$ & & - & - & $\begin{array}{l}\mathrm{R} \$ \\
12.000\end{array}$ \\
\hline Total & & & - & - & $\begin{array}{l}\mathrm{R} \$ \\
391.215,76\end{array}$ \\
\hline
\end{tabular}


BRANCO, J.R.O. et al. Viabilidade técnico-financeira de implantação do sistema de recria/engorda em uma propriedade de cria de bovinos no Município de Uberlândia-MG. PUBVET, Londrina, V. 5, N. 16, Ed. 163, Art. 1101, 2011.

\section{Tabela 14 - Animais}

\begin{tabular}{|c|c|c|c|c|c|}
\hline Éspecie & Categoria & Cabeças & @ & $\begin{array}{l}\text { Valor } \\
\text { Unitário } \\
(\mathrm{R} \$)\end{array}$ & $\begin{array}{l}\text { Valor Total } \\
(\mathrm{R} \$) \text {. }\end{array}$ \\
\hline \multirow[t]{7}{*}{ Bovino } & Vaca & 594 & 30 & 990 & 588.060 \\
\hline & Novilha & 230 & 22,6 & 740 & 170.200 \\
\hline & $\begin{array}{l}\text { Macho } \\
\text { (até } 3 \\
\text { anos) }\end{array}$ & 246 & 34 & $1.321,92$ & $325.192,32$ \\
\hline & $\begin{array}{l}\text { Macho } \\
\text { (até } 2 \\
\text { anos) }\end{array}$ & 248 & 24 & 860 & 213.280 \\
\hline & $\begin{array}{l}\text { Bezerra } \\
\text { (até } 7 \\
\text { meses) }\end{array}$ & 231 & 9,6 & 410 & 94.710 \\
\hline & $\begin{array}{l}\text { Bezerro } \\
\text { (até } 7 \\
\text { meses) }\end{array}$ & 250 & 10,4 & 590 & 147.500 \\
\hline & Touro & 15 & 50 & 2.200 & 33.000 \\
\hline Equino & Cavalo & 10 & 32 & 4.360 & 43.600 \\
\hline Total & & 1.578 & - & - & $1.615 .542,32$ \\
\hline $\begin{array}{l}\text { Rem. } \\
\text { Capital } \\
6 \%\end{array}$ & & - & - & - & $96.932,53$ \\
\hline
\end{tabular}

Tabela 15 - Serviços Contratados

\begin{tabular}{llllll}
\hline Tipo & Homens/dia & $\begin{array}{l}\text { Dias } \\
\text { trabalhados }\end{array}$ & $\begin{array}{l}\text { Valor } \\
\text { pago/dia }\end{array}$ & INSS & Total \\
\hline Tratorista & 01 & 20 & 40 & 21,6 & 821,6 \\
\hline Frete & 01 & 45 & - & - & 11.340 \\
\hline $\begin{array}{l}\text { Peão } \\
\text { (silo) }\end{array}$ & 02 & 20 & 35 & 18,9 & $1.437,80$ \\
\hline $\begin{array}{l}\text { Peão } \\
\text { (cerca) }\end{array}$ & 02 & 45 & - & - & $2.000,00$ \\
\hline Total & 05 & 45 & - & - & $15.589,40$ \\
\hline
\end{tabular}


BRANCO, J.R.O. et al. Viabilidade técnico-financeira de implantação do sistema de recria/engorda em uma propriedade de cria de bovinos no Município de Uberlândia-MG. PUBVET, Londrina, V. 5, N. 16, Ed. 163, Art. 1101, 2011.

Tabela 16 - Pagamentos a trabalhadores permanentes e temporários

\begin{tabular}{llllll}
\hline Cargo/Tarefa & Trabalhadores & $\begin{array}{l}\text { Dias } \\
\text { Trabalhados }\end{array}$ & $\begin{array}{l}\text { Salário } \\
\text { Mensal }\end{array}$ & Encargos & $\begin{array}{l}\text { Total } \\
\text { /anual }\end{array}$ \\
\hline Permanentes & & & & & \\
\hline Funcionários & 02 & 275 & 2000 & 214 & 26.568 \\
\hline Pró-Labore & 01 & 275 & 810 & 86,6 & 10.759 \\
\hline Veterinário & 01 & 30 & - & - & $58.104,60$ \\
\hline Sub-Total & 04 & - & & & \\
\hline Temporários & & & - & - & 822,00 \\
\hline Tratorista & 01 & 20 & - & - & 11.340 \\
\hline Frete & 01 & 45 & - & - & $1.437,80$ \\
\hline Peão (silo) & 02 & 20 & - & - & $2.000,00$ \\
\hline Peão (cerca) & 02 & 45 & - & - & $74.000,00$ \\
\hline Sub-Total & 05 & - & - & & - \\
\hline Total & 09 & & & $-444,60$ \\
\hline
\end{tabular}

Tabela 17 - Registro de Produção

\begin{tabular}{lllll}
\hline Produto & Unidade & $\begin{array}{l}\text { Produção } \\
\text { Vendida }\end{array}$ & $\begin{array}{l}\text { Preço } \\
\text { Unitário }\end{array}$ & Valor Total \\
\hline $\begin{array}{l}\text { Matrizes } \\
\text { para } \\
\text { descarte }\end{array}$ & Cab & 89 & 990 & 88.110 \\
\hline $\begin{array}{l}\text { Machos } \\
(36\end{array}$ & $@$ & 246 & 1.423 & $325.192,32$ \\
meses $)$ & & & & \\
\hline Novilhas & Cab & 135 & 740 & 99.900 \\
\hline Total & Cab & 470 & $1.144,82$ & $513.202,32$
\end{tabular}

Tabela 18 - Renda Bruta

\begin{tabular}{llll}
\hline Especificação & $\begin{array}{l}\text { Valor } \\
\text { Unitário }\end{array}$ & Valor Total & $\begin{array}{l}\% \\
\text { Receita }\end{array}$ \\
\hline Renda Bruta & & & \\
\hline $\begin{array}{l}\text { Venda } \\
\text { cabeças }\end{array}$ & $1.091,9$ & $513.202,32$ & 100 \\
\hline Total & $1.091,9$ & $513.202,32$ & 100 \\
\hline
\end{tabular}


BRANCO, J.R.O. et al. Viabilidade técnico-financeira de implantação do sistema de recria/engorda em uma propriedade de cria de bovinos no Município de Uberlândia-MG.

PUBVET, Londrina, V. 5, N. 16, Ed. 163, Art. 1101, 2011.

Tabela 19 - Custo de Produção Variável

\begin{tabular}{lllll}
\hline Especificação & Valor Total & $\begin{array}{l}\text { \%Custo } \\
\text { Variável }\end{array}$ & $\begin{array}{l}\text { \% Custo } \\
\text { Total }\end{array}$ & $\begin{array}{l}\text { Valor } \\
\text { Unitário }\end{array}$ \\
\hline $\begin{array}{l}\text { CUSTO DE PRODUÇÃO } \\
\text { VARIÁVEL }\end{array}$ & & & & \\
\hline Custo Operacional Variável & & & & \\
\hline Mão-de-obra temporária & $15.589,40$ & 0,04 & 0,02 & 33,16 \\
\hline $\begin{array}{l}\text { Manutenção de máquinas e } \\
\text { equipamentos }\end{array}$ & $4.284,00$ & 0,01 & 0,007 & 9,11 \\
& & & & \\
\hline Manutenção de instalações & $12.973,90$ & 0,03 & 0,02 & 27,6 \\
\hline Sal mineral & $19.529,10$ & 0,05 & 0,03 & 41,55 \\
\hline Sal proteinado & $83.555,55$ & 0,24 & 0,14 & 177,7 \\
\hline Silagem milho & $118.219,14$ & 0,34 & 0,2 & 251,53 \\
\hline Calcário & $4.800,00$ & 0,01 & 0,008 & 10,2 \\
\hline Gesso & $1.680,00$ & 0,004 & 0,002 & 3,57 \\
\hline Adubo npk 10-10-10 & $19.392,00$ & 0,05 & 0,03 & 41,25 \\
\hline Energia & 21.000 & 0,06 & 0,03 & 44,68 \\
\hline Combustível & 9.125 & 0,02 & 0,01 & 19,41 \\
\hline Telefone & 3.600 & 0,01 & 0,006 & 7,65 \\
\hline Vacinação & $5.390,30$ & 0,01 & 0,009 & 11,4 \\
\hline Vermifugação & 990 & 0,002 & 0,001 & 2,1 \\
\hline Medicamentos & 12.000 & 0,03 & 0,021 & 25,53 \\
\hline Sub-Total & $332.128,39$ & 0,97 & 0,58 & 706,65 \\
\hline Custo Alternativo Variável & & & & 212 \\
\hline Remuneração do capital & $9.963,85$ & 0,03 & 0,01 & 728 \\
circulante (3\%) & & & & 0,01 \\
\hline Sub-Total & $9.963,85$ & 0,03 & $60,60 \%$ & \\
\hline Total & $342.092,24$ & $100 \%$ & & \\
\hline & & & & \\
\hline
\end{tabular}


BRANCO, J.R.O. et al. Viabilidade técnico-financeira de implantação do sistema de recria/engorda em uma propriedade de cria de bovinos no Município de Uberlândia-MG. PUBVET, Londrina, V. 5, N. 16, Ed. 163, Art. 1101, 2011.

\section{Tabela 19 - Custo de Produção Fixo}

\begin{tabular}{lllll}
\hline Especificação & Valor Total & $\begin{array}{l}\% \text { Custo } \\
\text { Fixo }\end{array}$ & $\begin{array}{l}\% \text { Custo } \\
\text { Total }\end{array}$ & $\begin{array}{l}\text { Valor } \\
\text { Unitário }\end{array}$ \\
\hline $\begin{array}{l}\text { CUSTO PRODUÇÃo } \\
\text { FIXO }\end{array}$ & & & & \\
\hline Custo Operacional fixo & & & & 123,62 \\
\hline $\begin{array}{l}\text { Mão-de-obra } \\
\text { permanente }\end{array}$ & $58.104,60$ & 0,26 & 0,10 & 8,36 \\
\hline $\begin{array}{l}\text { Depreciação máquinas } \\
\text { e equipamentos }\end{array}$ & $3.932,30$ & 0,01 & 0,006 & \\
\hline $\begin{array}{l}\text { Depreciação } \\
\text { Instalações }\end{array}$ & $22.706,60$ & 0,1 & 0,04 & 48,31 \\
\hline Sub-Total & $84.743,50$ & 0,38 & 0,15 & 180,3 \\
\hline Custo Alternativo Fixo & & & & 5,77 \\
\hline $\begin{array}{l}\text { Remuneração capital } \\
\text { fixo }\end{array}$ & $2.712,50$ & 0,01 & 0,005 & \\
\hline Remuneração da terra & 135.000 & 0,6 & 0,23 & 287,23 \\
\hline Sub-Total & $137.712,50$ & 0,61 & 0,24 & 293 \\
\hline Total & $222.456,00$ & $100 \%$ & $39,40 \%$ & 473,31 \\
\hline
\end{tabular}

Tabela 20 - Custo Total de Produção

\begin{tabular}{lll}
\hline $\begin{array}{l}\text { Custo Total de } \\
\text { Produção }\end{array}$ & $\begin{array}{l}\% \\
\text { Custo }\end{array}$ \\
\hline Custo Fixo Total & $222.456,00$ & $39,40 \%$ \\
\hline Custo Variável Total & $342.092,24$ & $60,60 \%$ \\
\hline Custo Total & $564.548,24$ & $100 \%$ \\
\hline
\end{tabular}


BRANCO, J.R.O. et al. Viabilidade técnico-financeira de implantação do sistema de recria/engorda em uma propriedade de cria de bovinos no Município de Uberlândia-MG. PUBVET, Londrina, V. 5, N. 16, Ed. 163, Art. 1101, 2011.

Tabela 21 - Apuração dos Resultados

\begin{tabular}{l|l|l|l|l}
\hline Especificação & $\begin{array}{l}\text { Valor } \\
\text { Total }\end{array}$ & $\begin{array}{l}\text { Valor } \\
\text { Unitário }\end{array}$ & $\begin{array}{l}\% \\
\text { Receita }\end{array}$ & \% Custo \\
\hline RENDA BRUTA & 513.202 & $1.091,90$ & $100 \%$ & $\mathrm{x}$ \\
\hline $\begin{array}{l}\text { CUSTO DE } \\
\text { PRODUÇÃO }\end{array}$ & & & & \\
\hline $\begin{array}{l}\text { Custo Operacional } \\
\text { Variável }\end{array}$ & $332.128,39$ & 706,65 & $\mathrm{x}$ & 0,58 \\
\hline $\begin{array}{l}\text { Custo Operacional } \\
\text { Fixo }\end{array}$ & $84.743,50$ & 180,3 & $\mathrm{x}$ & 0,15 \\
\hline $\begin{array}{l}\text { Custo Operacional } \\
\text { Total }\end{array}$ & $416.871,89$ & 886,96 & $\mathrm{x}$ & 0,73 \\
\hline $\begin{array}{l}\text { Custo Alternativo } \\
\text { Variável }\end{array}$ & $9.963,35$ & 21,19 & $\mathrm{x}$ & 0,017 \\
\hline $\begin{array}{l}\text { Custo Alternativo } \\
\text { Fixo }\end{array}$ & $137.712,50$ & 293 & $\mathrm{x}$ & 0,24 \\
\hline $\begin{array}{l}\text { Custo Alternativo } \\
\text { Total }\end{array}$ & $147.675,85$ & 314,2 & $\mathrm{x}$ & 0,26 \\
\hline Custo Total & $564.547,74$ & 1201,16 & $\mathrm{x}$ & $100 \%$ \\
\hline $\begin{array}{l}\text { Renda Líquida } \\
\text { R.B - C.O.T) }\end{array}$ & $96.330,43$ & $\mathrm{x}$ & $\mathrm{x}$ & $\mathrm{x}$ \\
\hline $\begin{array}{l}\text { LUCRO (R.B - } \\
\text { C.T) }\end{array}$ & -51.345 & $\mathrm{x}$ & $\mathrm{x}$ & $\mathrm{x}$ \\
\hline
\end{tabular}

\section{Ponto de Nivelamento}
P. $\mathrm{N}=$ Ponto De Nivelamento
C.F.T $=$ Custo Fixo Total
P.u = Preço Unitário
C.V.T.u $=$ Custo Variável Total Unitário
P.N = C.F.T / (P.u - C.V.T.u)

C.F.T $=222.456,00$

P.u $=1.091,90$

C.V.T.u $=728$

$$
\begin{aligned}
& \text { P.N }=222.456 /(1.091,90-728) \\
& \text { P.N }=\mathbf{6 1 1}, \mathbf{3 1}
\end{aligned}
$$


BRANCO, J.R.O. et al. Viabilidade técnico-financeira de implantação do sistema de recria/engorda em uma propriedade de cria de bovinos no Município de Uberlândia-MG. PUBVET, Londrina, V. 5, N. 16, Ed. 163, Art. 1101, 2011.

Figura 4 - Gráfico Ponto de Nivelamento

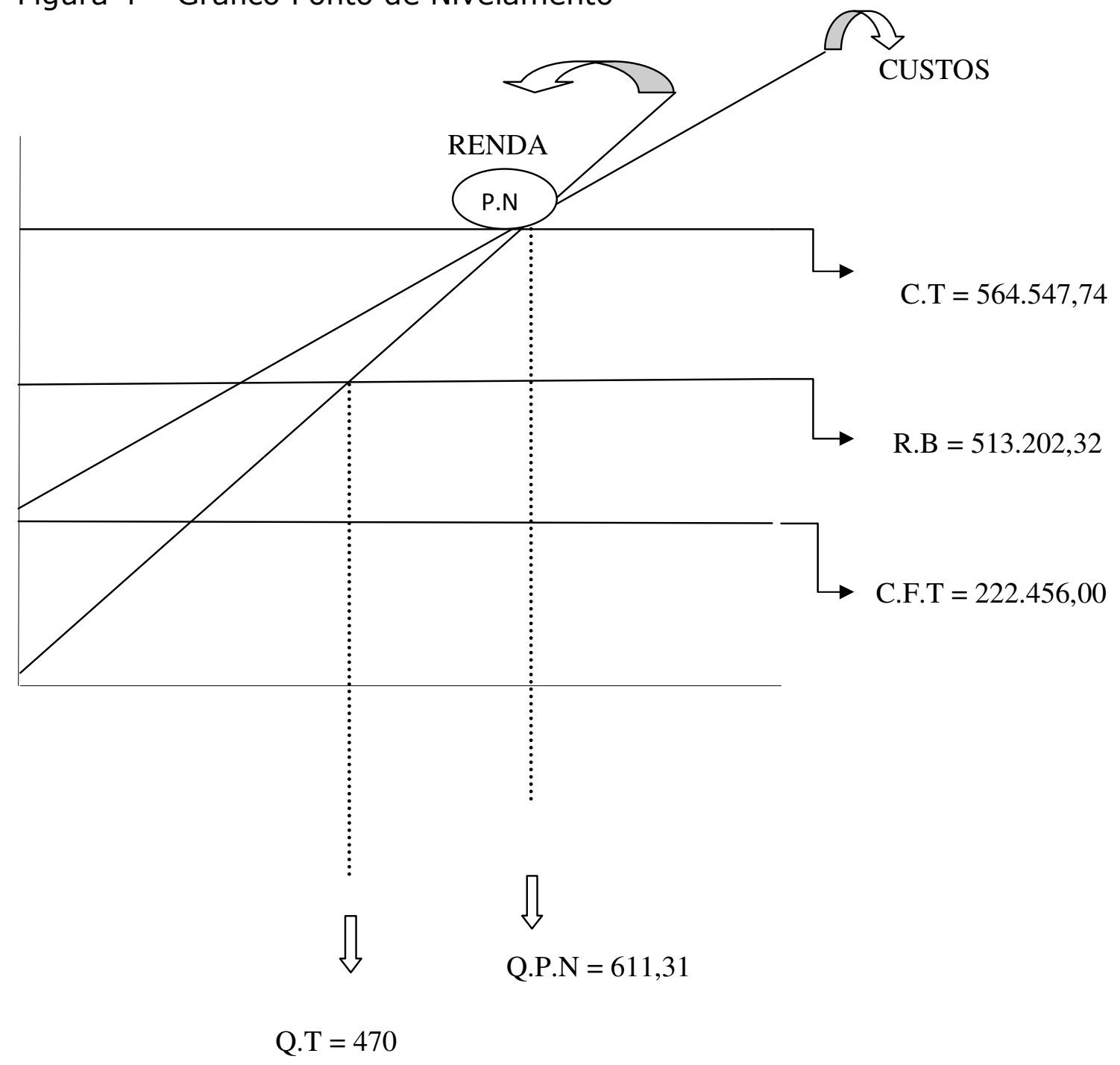

\section{Lucratividade}

A Lucratividade se dá pela subtração do custo total da renda bruta total, multiplicando por cem e dividindo pela renda bruta total.

LUCRATIVIDADE $=\{($ R.B - C.T $) * 100\} /$ R.B

LUCRATIVIDADE $=-10$ 
BRANCO, J.R.O. et al. Viabilidade técnico-financeira de implantação do sistema de recria/engorda em uma propriedade de cria de bovinos no Município de Uberlândia-MG. PUBVET, Londrina, V. 5, N. 16, Ed. 163, Art. 1101, 2011.

\section{Capacidade de Investimento}

A Capacidade de Investimento é determinada pela subtração do custo operacional total da renda bruta total, multiplicando por 100 e dividindo pela renda bruta total.

CAP. INVESTIMENTO $=\{($ R.B - C.O.T $) * 100\} /$ R.B

CAP. INVESTIMENTO $=18,77 \%$

\section{Retorno de Investimento}

O Retorno de Investimento é calculado dividindo a renda líquida pelo capital total e multiplicando por 100.

RET. INVESTIMENTO $=($ R.L $/$ C.T $) * 100$

É Renda Líquida: 96.330,43

É Capital Total: $\quad$ Capital Total Valor $(\mathrm{R} \$)$

\begin{tabular}{ll}
\hline Terras & 4.500 .000 \\
\hline Máquinas & $69.636,55$ \\
implementos & \\
\hline Construções & $472.857,98$ \\
e & \\
Instalações & \\
\hline Insumos & $391.215,76$ \\
\hline Animais & $1.615 .546,32$ \\
\hline Total & $7.049 .256,61$ \\
\hline
\end{tabular}

RET. INVESTIMENTO $=1,3$ 
BRANCO, J.R.O. et al. Viabilidade técnico-financeira de implantação do sistema de recria/engorda em uma propriedade de cria de bovinos no Município de Uberlândia-MG. PUBVET, Londrina, V. 5, N. 16, Ed. 163, Art. 1101, 2011.

\section{Análise de Rentabilidade}

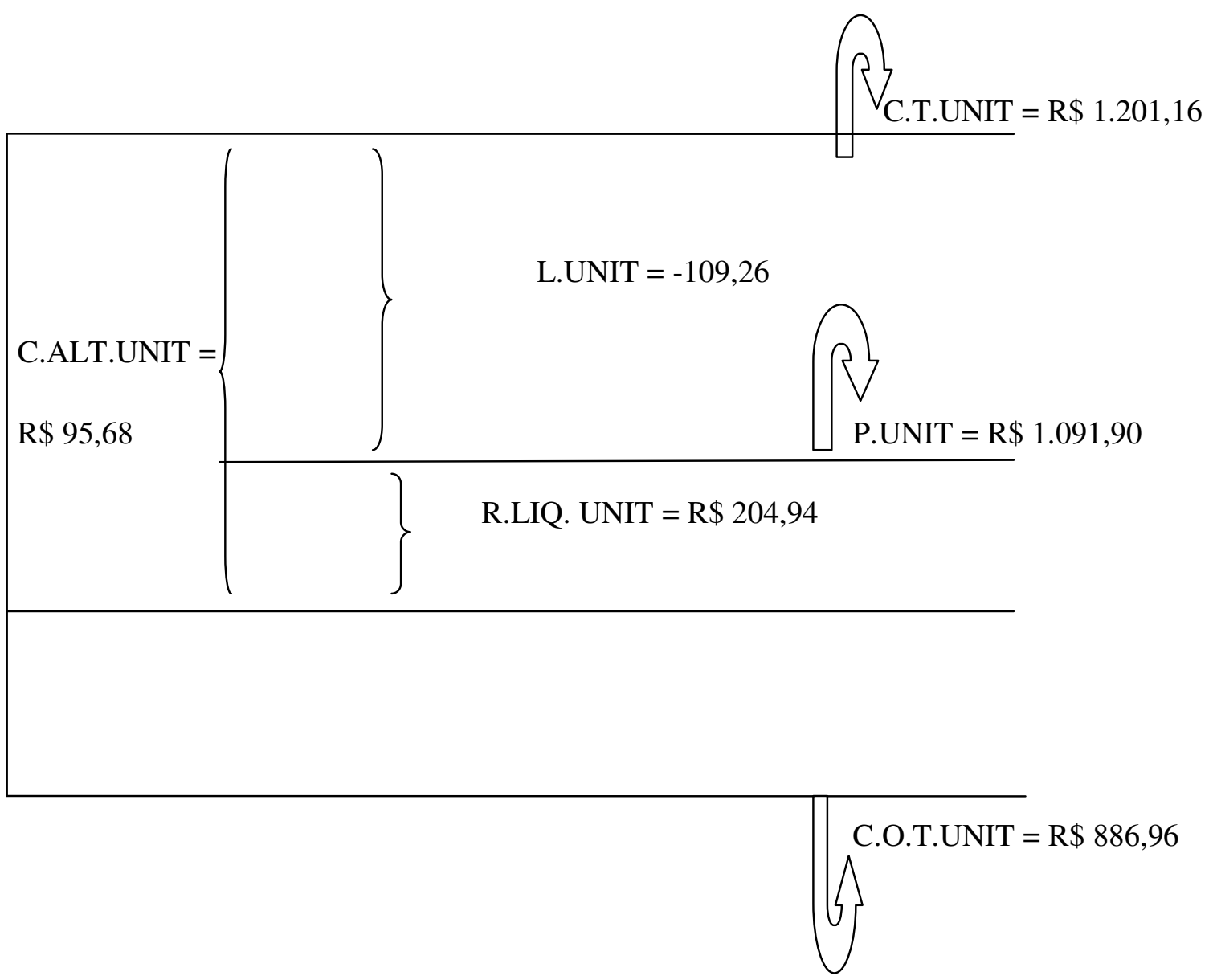

A propriedade apresenta uma situação de Lucro Operacional, onde ela produz o bastante para arcar com gastos do custo de produção e proporcionar um retorno, embora menor do que o valor dos custos alternativos. Nesta situação a fazenda apresenta um preço unitário, menor que o custo total unitário, porém, maior do que o custo operacional total unitário. 
BRANCO, J.R.O. et al. Viabilidade técnico-financeira de implantação do sistema de recria/engorda em uma propriedade de cria de bovinos no Município de Uberlândia-MG. PUBVET, Londrina, V. 5, N. 16, Ed. 163, Art. 1101, 2011.

\section{Resultados}

\section{Comparação entre os resultados obtidos nos métodos de Cria e Cria/Recria/Engorda intensiva, sendo aquele M1 e esse M2. Comparação do Desenvolvimento Econômico ao longo do projeto}

\section{Renda Líquida}

Figura 5 - Gráfico Renda Líquida

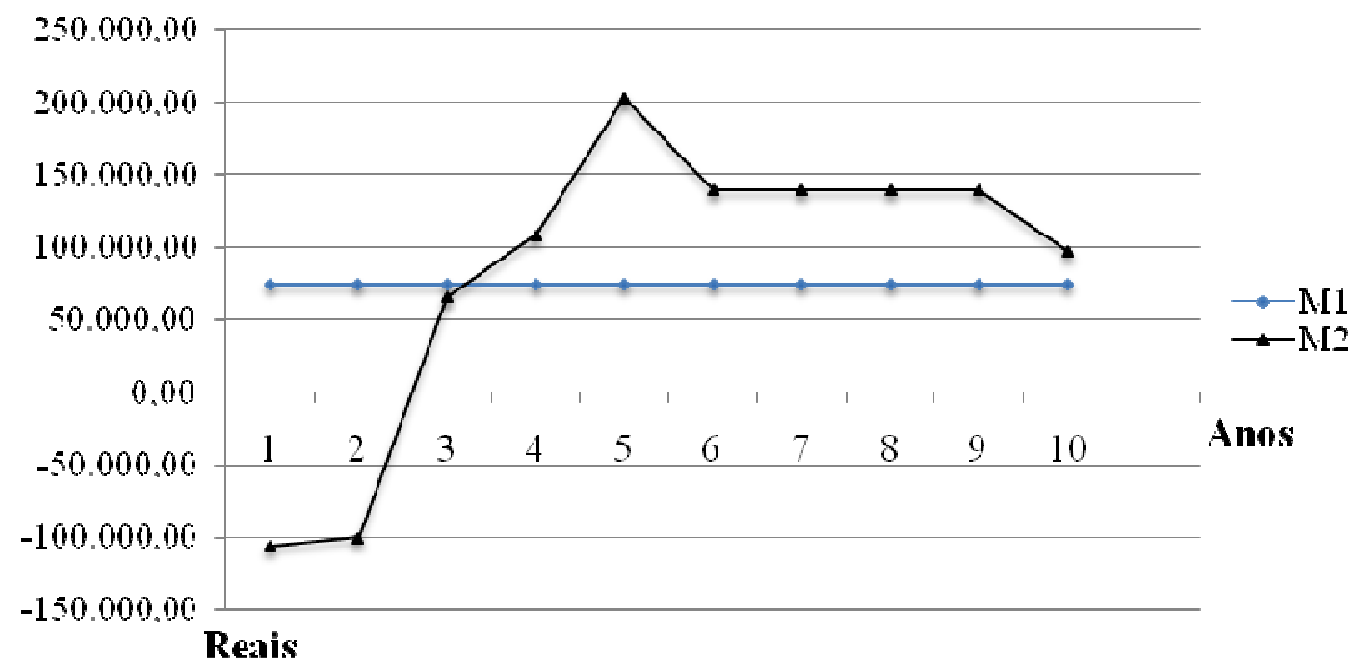

O gráfico acima mostra a renda líquida de M1 já estabilizada desde o início, enquanto M2 vai estabilizar-se somente a partir do décimo e último ano do projeto. Vale à pena ressaltar que a renda líquida do primeiro ao nono ano não apresenta embutidas as saídas ocasionadas pelos investimentos assim como as entradas via financiamentos. O décimo ano será utilizado como base de comparação para com o desempenho atual, pois nele já estão quitadas as parcelas dos financiamentos e o que era considerado investimento passa a assumir papel de custo fixo e variável incorporando também remunerações de capital e depreciações. 
BRANCO, J.R.O. et al. Viabilidade técnico-financeira de implantação do sistema de recria/engorda em uma propriedade de cria de bovinos no Município de Uberlândia-MG. PUBVET, Londrina, V. 5, N. 16, Ed. 163, Art. 1101, 2011.

\section{Saldo}

Figura 6 - Gráfico Saldo

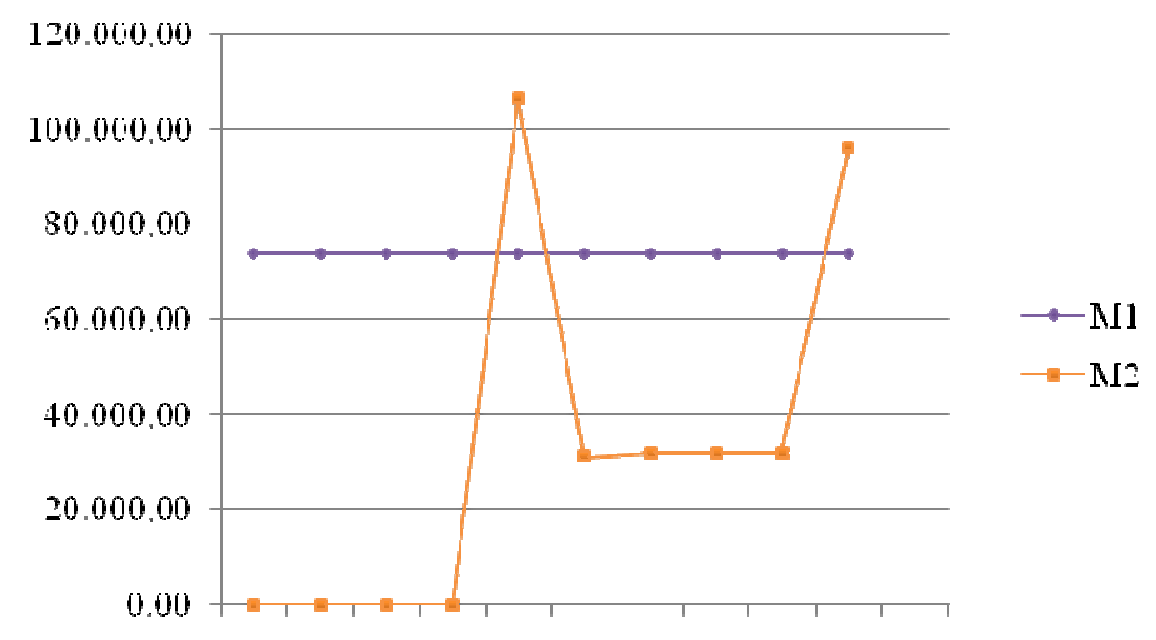

Reais $1 \begin{array}{lllllllllll} & 2 & 3 & 4 & 5 & 6 & 7 & 8 & 9 & 10 & \text { Anos }\end{array}$

O gráfico acima mostra o saldo obtido na propriedade incluindo investimentos e financiamentos. Observa que novamente M1 apresenta-se sem alterações. Nota-se também que M2 possui o mesmo resultado (R $\$ 96.330,43$ ) no décimo ano que o gráfico de Renda Líquida. Isso permite calcular, após encontrar o valor do saldo acumulado, o tempo que M2 leva até recuperar a soma adquirida por M1 ao longo do tempo do projeto. 
BRANCO, J.R.O. et al. Viabilidade técnico-financeira de implantação do sistema de recria/engorda em uma propriedade de cria de bovinos no Município de Uberlândia-MG. PUBVET, Londrina, V. 5, N. 16, Ed. 163, Art. 1101, 2011.

\section{Saldo Acumulado}

Figura 7 - Gráfico Saldo Acumulado

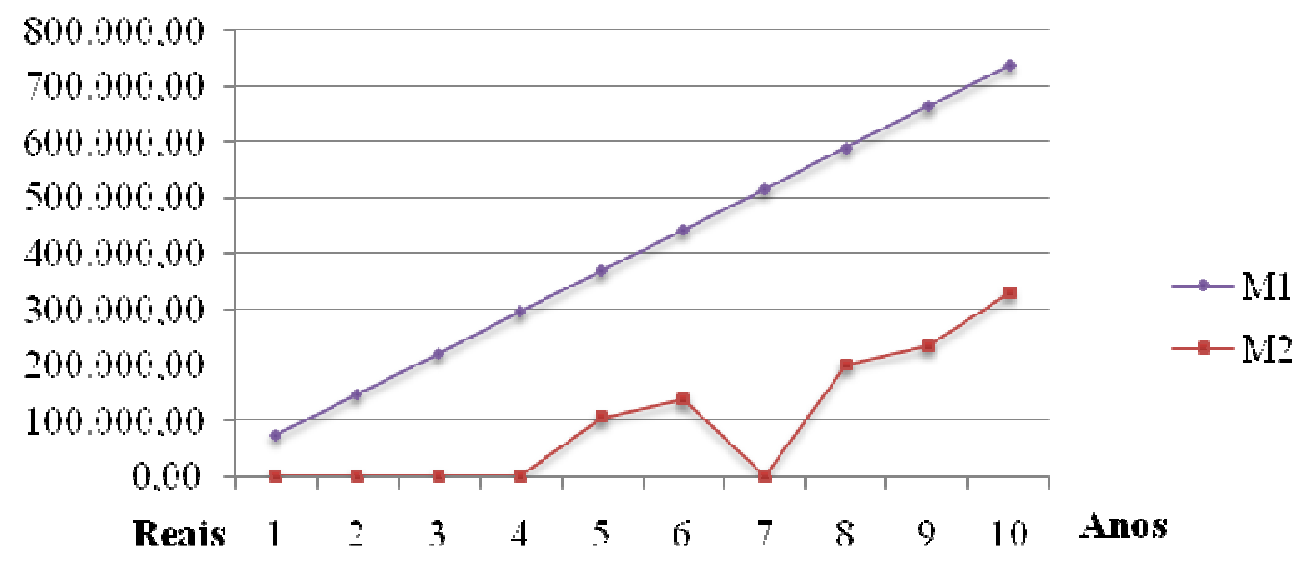

No gráfico de saldo acumulado é possível observar a diferença ao fim dos dez anos entre M1 e M2. M1 chega ao final com R $\$ 737.594,50$, ao passo que M2 com $R \$ 330.321,04$, indicando uma diferença de $R \$ 407.273,46$.

Como há estabilização financeira após a implantação do projeto é possível calcular o tempo de recuperação do capital acumulado por M1 ao longo dos dez anos. É esse tempo em anos de 18,07. Tempo esse calculado dado à diferença anual ao fim do projeto de $R \$ 22.527,55$ de saldo para M2 sobre M1.

\section{Comparação do Desempenho Econômico}

Tabela 22 - Tabela em R\$do desempenho das duas atividades

\begin{tabular}{llllll}
\hline & R.B & C.O.T & C.T & R.L & LUCRO \\
\hline M1 & $292.280,00$ & $218.703,95$ & $360.759,45$ & $73.576,05$ & -68.479 \\
\hline M2 & 513.202 & $416.871,89$ & $564.547,74$ & $96.330,43$ & -51.345 \\
\hline
\end{tabular}

Os dois métodos trabalham com Lucro operacional. Isso significa que das duas maneiras o produtor consegue arcar com as despesas onde há 
BRANCO, J.R.O. et al. Viabilidade técnico-financeira de implantação do sistema de recria/engorda em uma propriedade de cria de bovinos no Município de Uberlândia-MG. PUBVET, Londrina, V. 5, N. 16, Ed. 163, Art. 1101, 2011.

desembolso efetivo, porém M2 apresenta um acréscimo de $\mathrm{R} \$ 22.527,55$ ao ano.

\section{Tabela 23 - Tabela de comparação entre os principais índices de resultado econômico}

\begin{tabular}{llll}
\hline Tipo de índice & Unidade & M1 & M2 \\
\hline Lucratividade & $\%$ & $-23,4$ & -10 \\
\hline Rentabilidade & $\%$ & 1,19 & 1,36 \\
\hline $\begin{array}{l}\text { Cap. } \\
\text { Investimento }\end{array}$ & $\%$ & 25,17 & 18,77 \\
\hline
\end{tabular}

A tabela acima mostra que M2, apesar de possuir um custo total de produção maior, apresenta uma melhor lucratividade, que seria o quanto um produto apresenta de resultado em relação ao seu preço de venda e custo de produção. Nota-se também uma melhor rentabilidade, o que indica que M2 apresenta uma melhor relação entre o lucro obtido e o total do capital aplicado na atividade. A rentabilidade seve como parâmetro para comparações junto às melhores opções do mercado.

A capacidade de Investimento, que indica a sobra do capital após desembolsos efetivos com custos operacionais, mostra certa vantagem para M1, já que apesar de possuir uma renda bruta menor, tem uma relação renda bruta/custo operacional total maior.

\section{Discussão}

Primeiramente, pode-se dizer que: Sim, é viável a implantação do método de Recria/Engorda na Fazenda Douradinho, porém, a resposta acima deve ser acompanhada de algumas colocações. Tanto M1 como M2 possuem vantagens e desvantagens. São elas:

M1 tem como vantagem o fato de possuir o rebanho e a parte financeira já estabilizada, no entanto, vale lembrar que em longo prazo, o fato da atividade explorar a terra sem acompanhamento tende a causar uma diminuição na 
BRANCO, J.R.O. et al. Viabilidade técnico-financeira de implantação do sistema de recria/engorda em uma propriedade de cria de bovinos no Município de Uberlândia-MG. PUBVET, Londrina, V. 5, N. 16, Ed. 163, Art. 1101, 2011.

produção da forrageira, que já não apresenta um bom desempenho. M1 possui menos animais, consequentemente, menos desafios a serem transpostos.

M2 por outro lado, mostra um tempo de escassez financeira, já que a propriedade terá que passar por uma fase implantação. Porém, após o retorno do capital investido a fazenda obtém melhores resultados que M1. Como grande fator positivo, M2 têm ao seu lado o fato de aumentar bruscamente o patrimônio bruto do proprietário, já que aumenta o número de animais e instalações.

Definitivamente, M2 envolve um processo trabalhoso de transição, mas além dos melhores resultados, cuida melhor da fazenda no que se refere à questão zootécnica. Trabalha melhor com a forragem, aproveitando-a ao extremo, e ainda assim, sem causar a degradação causada por M1, já que passa a existir um cronograma de adubação.

\section{Conclusão}

Após análise e comparação entre os métodos conclui-se que o método de Recria/Engorda extensiva não apresenta viabilidade alguma de implantação da Fazenda Douradinho, tendo em vista sua aparente ineficácia.

Entre a Cria, utilizada atualmente, e a implantação da Recria/Engorda de maneira racional, pode-se notar certa vantagem para este dentro de uma análise de desempenho, porém, com tempo de retorno longo para os anos de adaptação da propriedade.

\section{Referências}

BENEDETTI, E.; Produção de leite a pasto no cerrado brasileiro. Anais do $3^{\circ}$ Encontro de Produtores de F1 - Jornada Técnica sobre a Utilização de F1 para produção de leite. Uberlândia. $6 \mathrm{p}$.

BRANCO, R. H.; Degradação de Pastagens. Diminuição da Produtividade com o Tempo. Conceito de Sustentabilidade. 2000. 27p. Trabalho da disciplina de Forragicultura Departamento de Zootecnia do Centro de Ciências Agrárias da Universidade Federal de Viçosa, Viçosa, 2000.

CORRÊA, A. N. S.; Recria e engorda. MAPA - Ministério da Agricultura Pecuária e Desenvolvimento. Gado de corte. O produtor pergunta e a EMBRAPA responde. In: 
BRANCO, J.R.O. et al. Viabilidade técnico-financeira de implantação do sistema de recria/engorda em uma propriedade de cria de bovinos no Município de Uberlândia-MG. PUBVET, Londrina, V. 5, N. 16, Ed. 163, Art. 1101, 2011.

MAPA - Ministério da Agricultura Pecuária e Desenvolvimento. Gado de corte. 0 Produtor pergunta e a EMBRAPA responde. Brasília: Empresa Brasileira de Pesquisa Agropecuária - EMBRAPA, 1996. p. 41-46.

CREPALDI, S.A. Contabilidade na Pecuária. In: CREPALDI, S.A. Contabilidade Rural: uma abordagem decisorial. São Paulo: Atlas, 2005. cap. 10, p.211-224.

CREPALDI, S.A. Fluxo de caixa e análise econômico-financeira na atividade rural. In: CREPALDI, S.A. Contabilidade Rural: uma abordagem decisorial. São Paulo: Atlas, 2005. cap. 14 , p. 271-290.

CREPALDI, S.A. Operacionalização contábil na empresa rural. In: CREPALDI, S.A. Contabilidade Rural: uma abordagem decisorial. São Paulo: Atlas, 2005. cap. 5, p. 93100 .

EMATER-DF. Conceitos Financeiros. Brasília, 2 p. Disponível em:

< http://www.emater.df.gov.br/sites/200/229/agroinf/conceitosfinanc.pdf >

Acesso em 24 Abr 2009.

EMATER-MG. Sistemas de piquetes proporciona economia a produtor. Belo Horizonte, 2009. Disponível em < http://www.agrosoft.org.br/agropag/209907.htm>. Acesso em 27 Abr 2009.

FARAVIM, S.; Planejamento e gerenciamento da propriedade leiteira. São Paulo: Serviço Nacional de Aprendizagem Rural, 2008. 46p. Disponível em < http://www.faespsenar.com.br/cart/proleite/Proleite-Planejamentoegerenciamento.pdf. $>$. Acesso em: 23 Mar 2009.

GOMES, S. T.; O cálculo correto do custo de produção de leite. Revista Balde Branco, São Paulo, 2005. 6p.

MATOS, A. C.; A Busca de Resultados pela Produtividade. Empresário online. Nov 1998. Disponível em

http://www.icone.com.br/downloadlivre/EBook/Antigos/A\%20Busca\%20de\%20Resultados\%20 pela\%20Produtividade.doc>. Acesso em 19 Mai 2009.

MATOS, L. V.; CAMPELLO, E. F. C.; RESENDE, A. S.; PEREIRA, J. A. R.; FRANCO, A. A. Análise sócio-econômica do uso de moirões vivos na construção de cercas ecológicas. Plantio de Leguminosas Arbóreas para Produção de Moirões Vivos e Construção de Cercas Ecológicas, São Paulo, v. 36, n. 3. Dez 2005. Disponível em: <http://sistemasdeproducao.cnptia.embrapa.br/FontesHTML/Moirao/MoiraoVivoCercaEcologica Lindex.htm>. Acesso em: 26 Abr 2009.

MiRANDA, J. E. C.; REZENDE, H.; VALENTE, J. O.; Plantio de milho para silagem. Portal do agronegócio. Mai 2006. Disponível em: http://www.portaldoagronegocio.com.br/conteudo.php?id=23196>. Acesso em: 21 Mar 2009.

OLIVEIRA, R. L.; BARBOSA, M. A. A. F. Nutrição e manejo de bovinos de corte na fase de cria. Bovinocultura de corte; desafios e tecnologias. In: OLIVEIRA, R. L.; BARBOSA, M. A. A. F.; LADEIRA, M. M.; BAGALDO, A. R. Bovinocultura de corte: desafios e tecnologias. Salvador: EDUFBA, 2007. cap 2, p. 23-80. 
BRANCO, J.R.O. et al. Viabilidade técnico-financeira de implantação do sistema de recria/engorda em uma propriedade de cria de bovinos no Município de Uberlândia-MG. PUBVET, Londrina, V. 5, N. 16, Ed. 163, Art. 1101, 2011.

PAULINO, M. F. Suplementação Múltipla na Bovinocultura de Ciclo Curto. In: ANDRADE, I. F.; BUENO, G. D.; CAMPOS, L. C. C.; LINHARES, E. M.; JUNIOR, W. $2^{\circ}$ Simpósio de Pecuária de Corte: "Novos Conceitos na Produção Bovina". Lavras, 2002. cap. 8. p. 199-252.

PEIXOTO, A. M.; MOURA, J. C.; FARIA, V. P.; Fatores que interferem no crescimento de bovinos de corte após a desmama. In: LIMA, F. A. P. Simpósio sobre pecuária de corte. Piracicaba: Escola Superior de Agricultura "Luis de Queiroz", 1983. p. 109-126

PEIXOTO, A. M.; MOURA, J. C.; FARIA, V. P.; Sistemas de produção em Bovinos de Corte. In: SALOMONI, E. Simpósio sobre pecuária de corte. Piracicaba: Escola Superior de Agricultura 'Luis de Queiroz", 1983. p. 1-32.

PIRTOUSHEG, A.; Custo de produção em atividades agropecuárias. Uberlândia: 2002. 46p.

PIRTOUSHEG, A.; Custo de produção em atividades agropecuárias. Uberlândia: 2003. 20p.

Recria de Novilhas e Novilhos. AGPNP - Associação goiana dos produtores de Novilhos precoces. Goiânia. Disponível em: < http://www.agpnp.com.br/ > Acesso em 16 Mar 2009.

RIBEIRO, N. L. Escrituração Zootécnica: o que é, como se faz e para que serve. Maranhão: Universidade estadual do Maranhão, 2008. Disponível em: <http://www.farmpoint.com.br/?actA=9\&erroN=1\&areaID $=14$ \&referenciaURL= noticiaID $=4557$ 4 4

SILVA, L. L. Apostila de Microsoft Excel módulo 1. 2007 Disponível em: $<$ www.dombosco.net/resources/multimidia/files/anexos/1147087731 Apostila $\% 20$ de $\% 20$

Excel Mod1.pdf. > Acesso em: 14 Abr 2009.

TEODORO, M, S, R.; Produção e teor de Matéria Seca das Brachiaria Brizantha cv. Marandú e Brachiaria Hibrida cv. Mulato nas condições do Sudoeste Goiano. 2007. 56p. Tese de Monografia - Departamento de Zootecnia do Instituto de Ciências Agrárias das Faculdades Integradas de Mineiros Mineiros, 2007.

ZANINE, A. M.; Avaliação de Plantas Forrageiras: Conceitos e Métodos. 2003. 25p. Trabalho da disciplina de Forragicultura - Departamento de Zootecnia do Centro de Ciências Agrárias da Universidade Federal de Viçosa, Viçosa, 2003.

ZIMMER, A. H.; EUCLIDES, V. P. B.; MACEDO, M. C. M. Manejo de plantas forrageiras do gênero Brachiaria. In: PEIXOTO, A. M. Plantas Forrageiras de Pastagens. Piracicaba: FEALQ, 1995. cap. 5, p. 101-144. 